\title{
Large-Scale Pressurized Irrigation Systems Diagnostic Performance Assessment and Operation Simulation
}

\author{
Daniele Zaccaria \\ Division of Land and Water Resources Management \\ Mediterranean Agronomic Institute of Bari (CIHEAM-MAI B) \\ Bari \\ Italy
}

\section{Introduction}

According to what documented by several authors and institutions, in many areas of the world irrigation projects perform far below their potential (Small and Svendsen 1992) and, in most of the cases, unrealistic or out-dated designs, rigid water delivery schedules and operational problems are among the principal reasons for the poor performance (Plusquellec et al. 1994).

The assessment of actual performance and potential improvement of conveyance and distribution systems received greater attention in recent years, and this trend will most likely extend to the near future, given that public and private investments will be more addressed to modernization of ageing or poor-performing irrigation schemes rather than to development of new irrigated areas or to expansion of existing irrigation schemes. In the perspective of service-oriented management, existing irrigation systems should be periodically evaluated for their performance achievements relative to current and future objectives. This requires diagnostic methodologies to analyze system behavior, assess current performance, identify critical aspects and weaknesses, and to investigate potential improvements. In this domain, several authors (Small and Svendsen 1992; Murray-Rust and Snellen 1993; Burt and Styles 2004) reported a remarkable lack of analytical frameworks by means of which irrigation managers or professional auditors can assess current achievements and diagnose feasible ways to enhance performance in the future. On the other hand, as pointed out by Prajamwong et al. (1997), identifying and implementing improvement changes entail the collection of field measurements and the use of analytical tools for developing feasible alternative scenarios and for selecting the most effective measures with the greatest impact on system performance.

Bos et al. (2005) indicated that diagnostic assessments are usually made to gain an understanding of how irrigation functions, to diagnose causes of problems and to identify opportunities for enhancing performance so that actions can be taken to improve irrigation water management. The same authors reported that diagnostic assessments are to be carried out when difficult problems are identified through routine monitoring, or when 
stakeholders are not satisfied with the existing levels of irrigation delivery services being provided, and desire changes in system operation.

The core component of diagnostic assessment is represented by performance indicators, as their selection and application aim at understanding functional relationships and at developing performance statements about irrigations. In the rationale of diagnostic assessment, irrigation managers or auditors need first to acquire a good understanding of system behavior under different operating conditions, prior to using simulation and management-support tools for appraising improvement options, and then take or recommend appropriate decisions.

In this view, a sound methodology for analysis of the existing irrigation schemes and of the management needs under current and future delivery scenarios is strongly required. Monitoring a set of variables that characterize the behavior of a complex system (diagnosis), and evaluating the system response after alternative correcting measures (prognosis and simulation) represent the basic capabilities required to an analytical methodology for addressing modernization processes with accuracy. The diagnostic component should be used to analyze different aspects of system management, such as assessment of water demand, management of water supply, identification of current system management needs, evaluation of system design, capacity and performance. The simulation component should instead be capable of facilitating the appraisal of improvement options by evaluating the system response after modifications. Both the diagnosis and simulation phases should be based upon a set of properly-chosen performance indicators to account for the main variables effecting the system operation and for synthetically representing the state of the system with respect to defined management objectives.

In this perspective, the methodology proposed in this chapter enables to conduct diagnostic assessments, simulate alternative deliveries and operational scenarios, and evaluate performance achievements in large-scale pressurized irrigation systems, thus constituting an analytical basis to address modernization processes in such systems with greater accuracy than was done in the past.

\section{Rationale of the proposed methodology}

The approach and components utilized within the proposed methodology are outlined in Fig. 1. The first part of the methodology entails the generation of the flow demand hydrographs during peak-demand periods through the use of an agro-hydrological model named Hydro-GEN that performs the daily soil-water balance and the simulation of irrigation deliveries for all the cropped fields served by the distribution network. By aggregating the simulated flow hydrographs at hydrant, the model generates the flow demand configurations for the entire distribution network. The Hydro-GEN model, and its applications to a pressurized irrigation delivery system at different management levels, were described in detail by Zaccaria et al. (2011a) and Zaccaria et al. (2011b).

The generated water demand scenarios are spatially and time distributed estimates that may be then used to define the expected levels of irrigation delivery service (objectives setting) from the distribution network over the different serviced areas. The flow configurations in the distribution network are then passed as inputs to a hydraulic model named COPAM (Lamaddalena and Sagardoy 2000) to simulate deliveries under different conditions and 
operational modes, analyze the network's hydraulic behaviour and evaluate hydraulic performance achievements with regard to the target delivery objectives. In this way, the COPAM simulation model allows identifying the structural limitations and the potential failures of the irrigation delivery network under different simulated flow configurations.

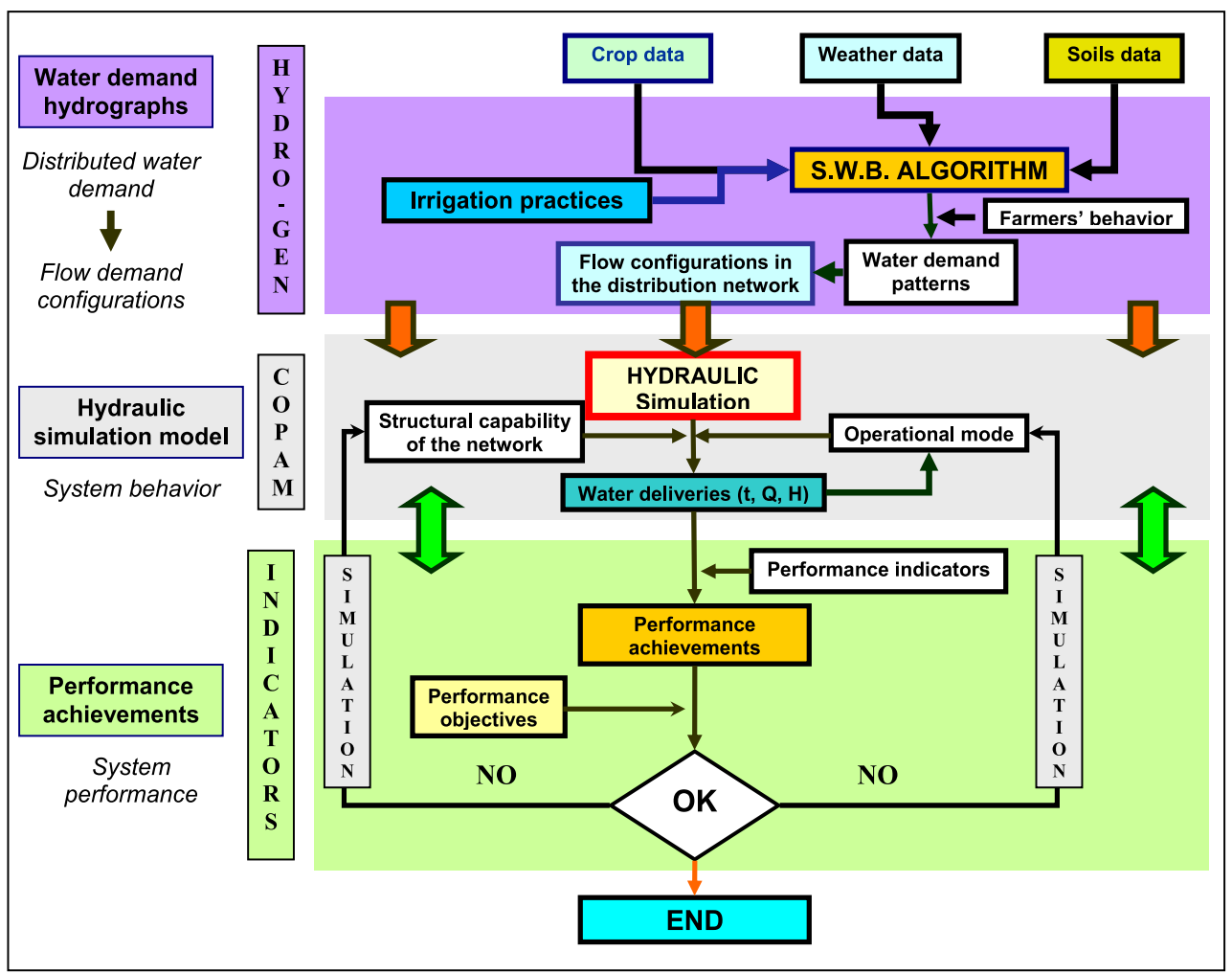

Fig. 1. Process and components utilized by the proposed methodology for conducting operational and performance analysis in pressurized irrigation systems.

The hydraulic simulations are based upon user-specified irrigation delivery conditions (or on agreed-upon delivery service between the water management body and the users) and utilize selected indicators and reference values to evaluate hydraulic parameters and identify the state of the system with respect to the specified management objectives. Moreover, the combined use of the Hydro-GEN and COPAM models verifies that the aggregated water demand and the adopted operational modes do not exceed the daily available water supply and the maximum physical conveyance and delivery capacity of the distribution network.

As final step, some additional indicators are applied to evaluate water delivery variables, other than hydraulic parameters, and to refine the performance assessment. The outputs resulting from simulations with the COPAM model, along with the evaluation of irrigation delivery by means of the additional indicators, can be interpreted in terms of performance 
achievements through the comparison with the users' requirements or the agreed-upon delivery conditions. Applying the above-described tools in the proposed sequence, and analyzing the resulting outputs, will guide the system managers and auditors in evaluating the irrigation delivery scenarios as satisfactory or unsatisfactory, and adjust the operations accordingly or identify the necessary physical changes.

\section{Description of main components}

\subsection{The HydroGEN model}

The approach and methodological steps utilized by the HydroGEN model for generating the flow demand hydrographs are illustrated in Fig. 2. HydroGEN consists of a deterministic component, represented by different terms of the soil-water balance equation, and a stochastic component that accounts for uncertainties and variability of some parameters related to crops and soils, as well as to farmers' habits and practices. The deterministic component enables the simulation of daily soil-water balances for all the individual

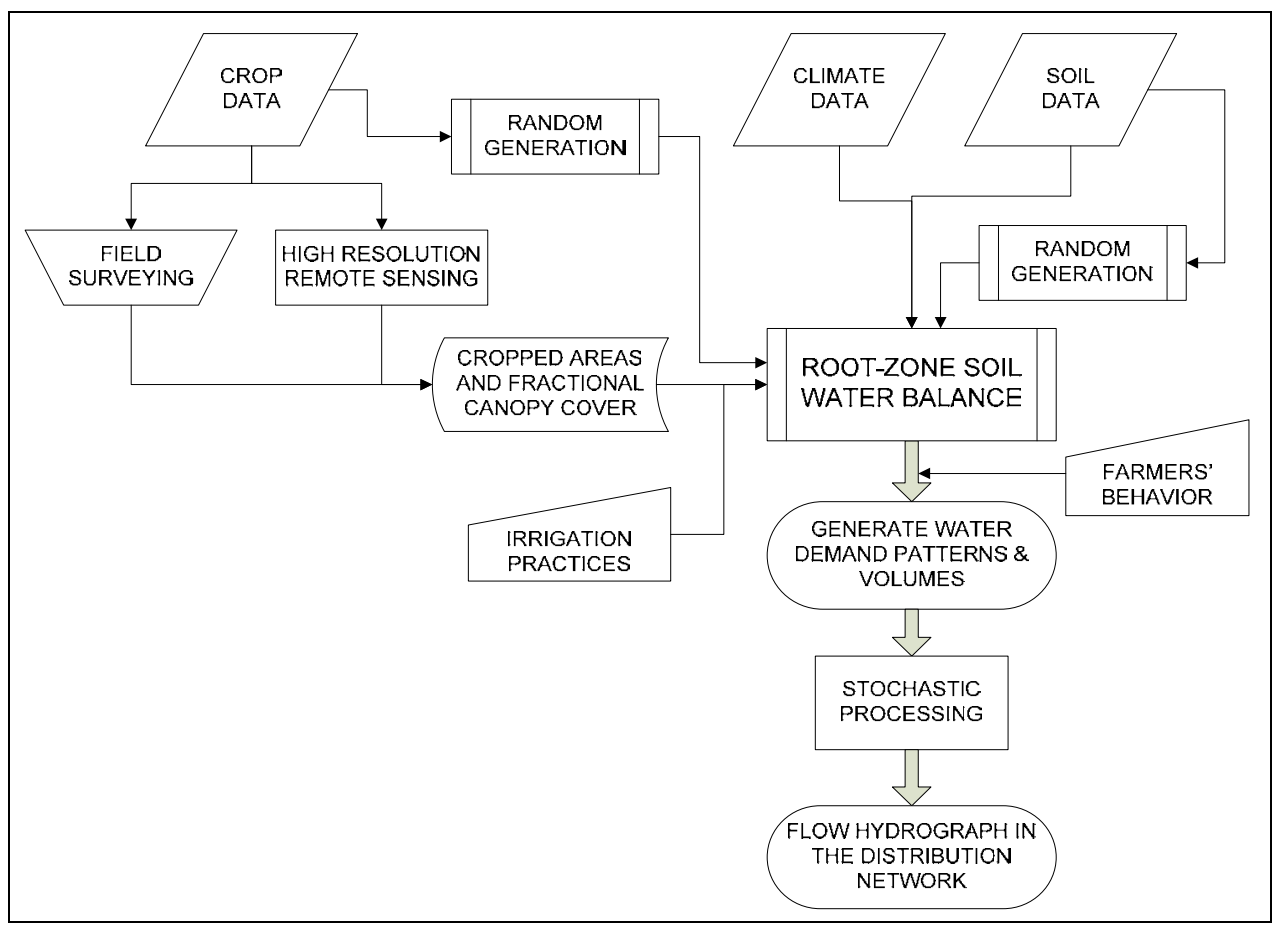

Fig. 2. Process utilized by HydroGEN to generate discharge hydrographs in pressurized irrigation systems.

cropped fields supplied by the water distribution network, based upon crop evapotranspiration estimated from daily climatic and rainfall data, crop type and stage of development, soil properties, and farm irrigation methods. The stochastic component enables the determination of some parameters of relevance to the computation of crop water 
demand and of timings of irrigation events, such as the sowing or green-up dates, and the initial soil water content at the beginning of the growing season. These parameters are strongly affected by uncertainties and are determined in HydroGEN by means of random generation within specific user-defined ranges, as described by Zaccaria et al. (2011a).

By integrating crop, soil and climatic data, HydroGEN simulates a series of daily irrigation demand volumes by maintaining a root-zone soil water budget for the cropped fields served by each delivery hydrant. In this process, the deterministic and stochastic components jointly allow generating disaggregated information on soil water deficits, and thus on timing and volumes of irrigation demand, both under conditions of full replenishment of soil water depletion and under regulated and/or deficit irrigation strategies.

These irrigation depths resulting from simulating the daily water balance and irrigation events are then aggregated upwards for all the cropped fields supplied by each hydrant, and then for all hydrants of the network, thus enabling the generation of a daily hydrograph of irrigation volumes demanded at different system management levels, i.e. at the hydrant, at single branches of the distribution network, at sector, district, or at the entire system level. As a subsequent step, HydroGEN identifies the 10-day peak-demand period by applying the method of the moving averages to the series of simulated daily irrigation demanded volumes.

Within the identified peak-demand period, HydroGEN then utilizes a stochastic procedure to determine the most likely timing of hydrants' openings and shut-offs during the daytime to deliver the required irrigation volumes. Based on the above determination, the daily irrigation volumes are translated into hourly flow rates and the number of hydrants in simultaneous operation hour-by-hour can be simulated. Therefore the hydrographs of hourly flow rates can be generated by aggregating on an hourly basis the flow rate demanded from these hydrants on an hourly basis. Likewise for the daily demanded volumes, based upon the level of aggregation, HydroGEN can simulate the hydrograph of hourly flow rates during the peakdemand period at hydrants, sector, district or system scale.

\subsection{The COPAM Model}

The Combined Optimization and Performance Analysis Model (COPAM) is a software package that provides computer-assisted capabilities for design and analysis of large-scale pressurized irrigation delivery networks. The model is described in details by Lamaddalena (1997) and by Lamaddalena and Sagardoy (2000) and is composed of three modules, one for the generation of demand discharges, one for the optimization of pipe size, and the third for the analysis of hydraulic performance. The synthetic process flow of COPAM is presented in Fig. 3.

As for the first module, the distribution of discharges flowing in the delivery network can be generated by using the Clément probabilistic method (Clément 1966; Clément and Galand 1979) or by means of the "Several Flow Regimes" approach (SFR) as proposed by Labye et al. (1988).

In COPAM, the flow computation through the SFR approach is implemented by means of the random generation of a certain number of hydrants in simultaneous operation, out of the total number of hydrants of the network, and the discharge in single sections of the 
network is thus computed as the sum of the discharges withdrawn from the downstream hydrants being in simultaneous operation, with the simplifying assumption that each open hydrant always delivers the nominal flow rate (Lamaddalena and Sagardoy 2000). Alternatively, the flow configuration in the pipe network can be read by COPAM as external file that results from simulating the demanded flow rates by means of the soil-water balance approach coupled with a stochastic processing through the HydroGEN model, as described in the previous section.

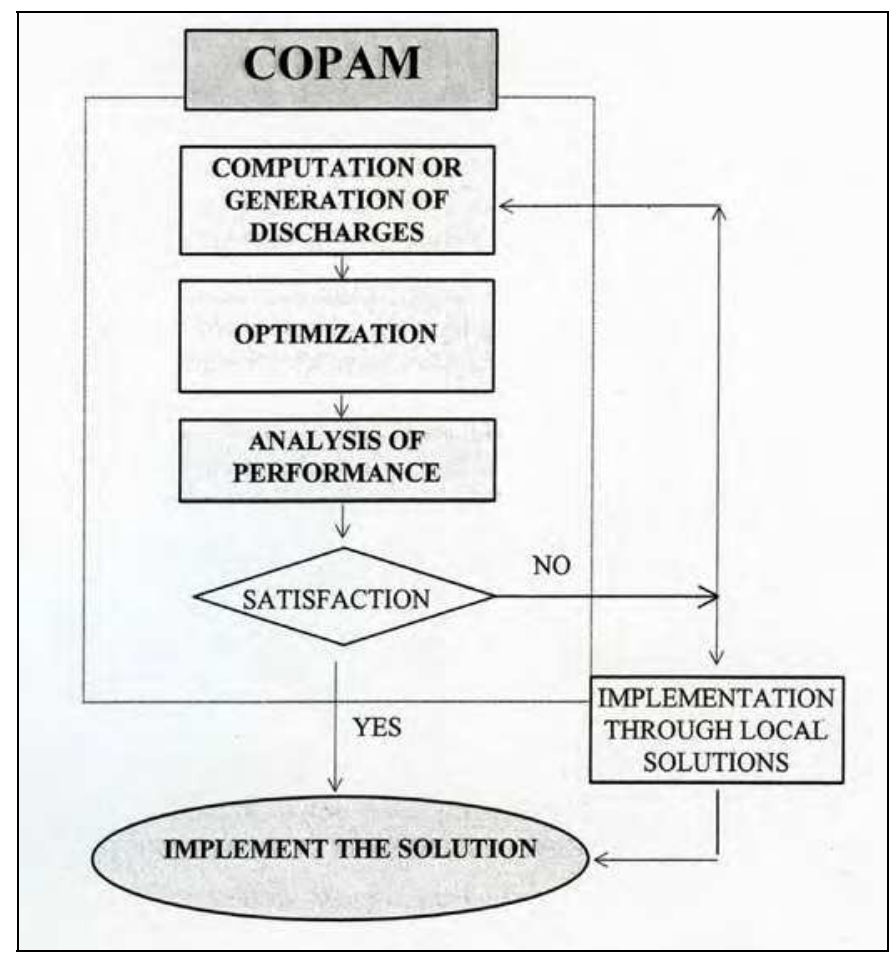

Fig. 3. Schematic process flow used by COPAM (Source: Lamaddalena and Sagardoy 2000).

The optimization module enables the computation of optimal pipe sizes in the whole network following the simulated flow configurations through the three possible alternatives previously mentioned: single flow regimes (Clément approach), several flow regimes (SFR) directly generated by the first module, and several flow regime previously generated by the first module, or simulated externally by the HydroGEN model and stored in a file to be read.

The performance achievable by the network tentatively designed by following the two above-described steps is then analyzed by means of two conceptual models, the Indexed Characteristic Curves model (CTGREF 1979; Bethery et al. 1981) and the AKLA model (Ait Kadi and Lamadalena 1991 - CIHEAM internal note not published), and based upon specific performance criteria. The Indexed Characteristic Curves model allows investigating a large number of configurations of hydrants in simultaneous operation, which correspond to a 
fixed value of the nominal discharge, $Q$, and to different values of the required piezometric elevation, $\mathrm{Z}$, at the inlet of the distribution network to satisfy the configurations. A configuration is considered satisfied when for all the hydrants in simultaneous operation the following relationship holds true:

$$
H_{j, r} \geq H_{R E Q}
$$

where $H_{\mathrm{j}, \mathrm{r}}(\mathrm{m})$ is the hydraulic head of the hydrant $j$ within the configuration $r$, and $H_{\mathrm{REQ}}(\mathrm{m})$ is the minimum required head for proper operation of farm irrigation systems.

After defining the values of the discharge $(Q)$ at the upstream section of the network, and the total number of configurations (C) to be investigated, a series of piezometric elevations $(\mathrm{Zr})$ at the inlet of the network able to satisfy a given percentage of $\mathrm{C}$ configurations can be associated to each value of the upstream discharge. In doing so, the indexed characteristic curves can be drawn by plotting in the plane $(Q, Z)$ the discharge values chosen and the corresponding required piezometric elevations, and by joining the points having the same percentage of configurations satisfied. The shape of these curves depends on the geometry of the network and on the topography of the commanded area.

The AKLA model enables the analysis of performance at each hydrant of the network under different operating conditions. The model is based on the multiple generation of a pre-fixed number of hydrants in simultaneous operation, with the hydrants being considered satisfied within each generated configuration when the Eq. 1 holds true for each selected hydrant. The model computes the discharge and pressure head resulting at each hydrant under different flow configurations, that is then compared with the minimum required pressure for the proper operation of the on-farm irrigation systems downstream of the hydrant itself. The measure of hydraulic performance achievements at each hydrant is thus obtained by means of the computation of the relative pressure deficit $\left(R P D_{j, r}\right)$ at the hydrant $j$ within the configuration $r$ of hydrants in simultaneous operation, through Eq. 2 reported in the following section, and of the percentage of unsatisfied hydrants out of the total number of hydrants in simultaneous operation. Therefore, for each configuration the range of variation of the pressure head at each hydrant can be determined, and the hydrants subject to insufficient pressure heads, and hence the most critical zones of the network, can be clearly identified.

\subsection{Performance indicators}

Performance indicators are parameters resulting from the mathematical combination of measurable state variables and are conceived to synthetically represent how the irrigation system behaves with respect to the achievement of planned, targeted or agreed-upon objectives. Many authors and institutions have proposed specific ways to measure performance of irrigation and drainage systems, and therefore there is a large set of indicators available in literature, as summarized by Rao (1993) and by Bos et al. (2005).

The proposed methodology for diagnostic assessment entails the use of some performance indicators that were specifically adapted to pressurized delivery systems for describing the achievements by the irrigation distribution network with respect to the targeted water delivery objectives. In detail, the Relative Pressure Deficit and Reliability at each hydrants 
were taken from previous works conducted by Lamaddalena (1997) and by Lamaddalena and Sagardoy (2000) and, in conjunction with the hydrant's Sensitivity, which was instead defined within the present research, were used to measure and describe the hydraulic performance of the irrigation delivery networks in terms of pressure heads at the delivery points.

Three additional indicators, namely the Relative Volume, the Relative Frequency, and the Relative Delay, were instead developed by modifying the indicator of Adequacy as it was originally conceived by Molden and Gates (1990) to conduct performance assessment in open channel networks. These modifications aimed at tailoring the objective of Adequacy to pressurized irrigation distribution systems and thus at describing the adequacy of water delivery in terms of supplied volumes and of timeliness of irrigation.

Finally, also the indicators of Dependability and of Equity were modified with respect to those defined by Molden and Gates (1990), and then used to assess the spatial and temporal variability of irrigation delivery conditions over the command areas and during the periods of interest.

The Relative Pressure Deficit at each hydrant, $R P D$, as defined by Lamaddalena (1997), is computed by Eq. 2.

$$
R P D_{j, r}=\frac{\left(H_{j, r}-H_{R E Q}\right)}{H_{R E Q}}
$$

where $H_{j, r}$ is the hydraulic head at the hydrant $j$ within the configuration $r$ of hydrants in simultaneous operation, and $H_{R E Q}$ is the minimum pressure head necessary for proper operation of on-farm irrigation systems.

The representation of $R P D_{j, r}$ in a plane where the abscissas correspond to hydrants' number and the ordinates to $R P D_{j, r}$ clearly identifies the hydrants having insufficient pressure for enabling proper on-farm irrigation.

As for the second indicator, in general terms the Reliability of a system describes how often the system fails or, in different terms, the frequency or probability of the system being in a satisfactory state. Following earlier works by Hashimoto (1980) and by Hashimoto et al. (1982), the mathematical definition of reliability at hydrant level was carried out by Lamaddalena (1997) as reported hereafter.

$$
\alpha=\operatorname{Pr} o b\left[X_{t} \in S\right]
$$

where $a$ is the hydrant's reliability, and $X_{t}$ is the random variable denoting the state of the system at time $t$.

The possible values of $X_{t}$ may fall in two sets: $S$, the set of all satisfactory outputs and $F$, the set of all unsatisfactory outputs denoting failure. Following this approach, at each instant $t$ the system may fall in one of these alternative sets. Therefore the reliability of a system can be described by the probability $a$ that the system is in a satisfactory set.

The state of satisfaction at hydrant level is measured on the basis of the value of the available hydraulic head at the hydrant under the different flow configurations, i.e. within each generated configuration $r$ of hydrants in simultaneous operation, a hydrant $j$ is considered satisfied when the Eq. 1 holds true. 
In the specific case of pressurized irrigation systems, the reliability of each hydrant expresses the variability over time of the available pressure head of irrigation water deliveries at hydrants during the period of interest. From the Eq. 3, the reliability of each hydrant can be computed on the basis of the Eq. 4 :

$$
\alpha_{j}=\frac{\sum_{r=1}^{C} I h_{j, r} I p_{j, r}}{\sum_{r=1}^{C} I h_{j, r}}
$$

where

$a_{j}=$ reliability of the hydrant $\mathrm{j}$

$I h_{j, r}=1$, if the hydrant, $\mathrm{j}$, is open in the configuration $\mathrm{r}$

$I h_{j, r}=0$, if the hydrant, $\mathrm{j}$, is closed in the configuration $\mathrm{r}$

$I p_{j, r}=1$, if the pressure head at the hydrant, $\mathrm{j}$, open in the configuration $\mathrm{r}$, is higher than the minimum required pressure head

$I p_{j, r}=0$, if the pressure head at the hydrant, $\mathrm{j}$, open in the configuration $\mathrm{r}$, is lower than the minimum required pressure head

$C=$ total number of generated configurations.

After estimating the available pressure head $(\mathrm{m})$ at each hydrant in operation under each flow configuration within the network, the COPAM model calculates the values of the parameters $I h_{j, r}$ and $I p_{j, r}$, thus computing the corresponding value of the hydrant reliability, $a_{j}$.

The sensitivity of hydrants, also named as Relative Pressure Deficit Sensitivity, RPDS, refers to the range of fluctuations of the relative pressure deficit occurring at the delivery points, and how this range stretches across the zero-value line of $R P D$. This in turn identifies the adequacy in the available pressure head with respect to the minimum required value, $H_{R E Q}$, for having the on-farm irrigation systems working properly. In detail, the minimum boundary of the range of $R P D$ fluctuations is relevant for identifying both the potential failures and their severity. The sensitivity of hydrants is calculated through the Eq. 5:

$$
\begin{gathered}
R P D S=R P D_{A V E}-0.5 * R P D_{R A N G E}=\left(\frac{H_{A V E}-H_{R E Q}}{H_{R E Q}}\right)-0.5 *\left(R P D_{M A X}-R P D_{M I N}\right) \\
\Rightarrow \text { RPDS }=\left(\frac{H_{A V E}-H_{R E Q}}{H_{R E Q}}\right)-0.5 *\left[\left(\frac{H_{M A X}-H_{R E Q}}{H_{R E Q}}\right)-\left(\frac{H_{M I N}-H_{R E Q}}{H_{R E Q}}\right)\right]
\end{gathered}
$$

where the limits of $H_{M I N}$ and $H_{M A X}$ are set as follows:

$$
\begin{gathered}
H_{\text {MIN }} \geq 0 \\
H_{\text {MAX }} \leq \text { Max operating pressure head bearable by pipes }
\end{gathered}
$$

The Relative Volume, $R V$, is a measure of the objective of the distribution network of delivering adequate irrigation volumes to each serviced cropped field with respect to the 
required ones. The $R V$ is therefore a measure of Adequacy expressed in terms of delivered volumes and is defined by the following relationships:

a. at a given location

$$
R V=\frac{V_{D E L I}-V_{R E Q}}{V_{R E Q}}
$$

b. averaged over the region, $\mathbf{R}$, and the time of interest, $\mathbf{T}$

$$
P_{A V}=\frac{1}{T} \sum_{T}\left(\frac{1}{R} \sum_{R} R V\right)
$$

where $V_{D E L I}$ and $V_{R E Q}$ are the irrigation volume delivered by the distribution network and the irrigation volume required for adequate crop irrigation management and target yield, respectively.

As for the objective of Adequacy in terms of timeliness of irrigation delivery, the Relative Frequency, $R F$, and the Relative Delay, $R D e$, were defined by the equations reported hereafter.

$R F$

a. at a delivery location:

$$
R F=\frac{F_{R E Q}-F_{D E L I}}{F_{R E Q}}
$$

b. and the average over the region, $\mathrm{R}$, and during the time of interest, $\mathrm{T}$ :

$$
P_{A F}=\frac{1}{T} \sum_{T}\left(\frac{1}{R} \sum_{R} R F\right)
$$

where $F_{R E Q}$ is the frequency of irrigation required by any combinations crop/soil/climate for not incurring in any soil water deficit, and $F_{D E L I}$ is the frequency of actual irrigation water delivery by the distribution network.

RDe

a. at a delivery location:

$$
R D e=\frac{D E L_{A L L}-D E L_{D E L I}}{D E L_{A L L}}
$$

b. averaged over the region, $R$, and time of interest, $T$ :

$$
P_{A D}=\frac{1}{T} \sum_{T}\left(\frac{1}{R} \sum_{R} R D e\right)
$$

where $D E L_{A L L}$ is the maximum allowed delay (days) of irrigation that would cause a yield reduction within $10 \%$ of the maximum obtainable yield due to soil water deficit, for any 
given combinations crop/soil/climate, and DEL $L_{D E L I}$ is the actual delay of irrigation delivery (days) by the distribution network with respect to the required timing for achieving the maximum yield (no water deficit).

The $R V, R F$ and $R D e$ are particularly meaningful when the distribution network is operated by rotation or by arranged delivery schedules, whereas when irrigations are under the farmers' control (demand delivery schedules) the timing of irrigations and the volumes withdrawn from the network by farmers and applied to cropped fields are more affected by the available water supply, by the network delivery capacity as well as by farmers' habits and behavior rather than by the network operations. Indirectly, the irrigation events and the volumes withdrawn by farmers are also affected by the pressure head available at hydrants under the different flow configurations. At the same time, hydrants' operation, flow rates and volumes withdrawn by farmers strongly affect the flow configurations in the different sections of the network and thus the conditions of water delivery to other hydrants. As a matter of fact, in pressurized delivery systems operated on-demand, when farmers open the hydrants and do not find adequate pressure head for proper on-farm irrigation, they usually shut-off the hydrant and return sometime later for irrigating their fields. In other words, water withdrawals by farmers at given hydrants might be biased by the operation of other hydrants and by the behavior of other farmers and, at the same time, they might affect the operation of other hydrants as well, especially when the distribution network has low delivery capacity or low flexibility. Thus, the $R V$, together with $R P D, R F$ and $R D e$ indicate indirectly the network performance or, in other words, the capability of the distribution network to accommodate the farmers' behavior and the farming practices followed in the entire command area, and to still deliver water with the required conditions.

The indicator of Dependability expresses the temporal uniformity of the conditions of irrigation delivery. When the concerned delivery parameter is the irrigation volume the dependability refers to the degree of temporal variability of the $R V$ that occurs over the region of interest, $R$, and is expressed by the Eq. 12 :

$$
P_{D}=\frac{1}{R} \sum_{R} C V_{T}(R V)=\frac{1}{R} \sum_{R} C V_{T}\left(\frac{V_{D E L I}-V_{R E Q}}{V_{R E Q}}\right)
$$

where $C V_{T}\left(\frac{V_{D E L I}-V_{R E Q}}{V_{R E Q}}\right)=$ temporal coefficient of variation (ratio of standard deviation to mean) of the RV over the time period of interest $\mathrm{T}$ (i.e. variability from time to time over the period $\mathrm{T}$ ).

When the concerned delivery parameter is the timeliness of irrigation, the dependability is expressed in terms of temporal variability of $R F$ and/or of $R D e$ as follows:

$R F$ :

$$
P_{D}=\frac{1}{R} \sum_{R} C V_{T}(R F)=\frac{1}{R} \sum_{R} C V_{T}\left(\frac{F_{R E Q}-F_{D E L I}}{F_{R E Q}}\right)
$$


where $C V_{T}\left(\frac{F_{R E Q}-F_{D E L I}}{F_{R E Q}}\right)=$ temporal coefficient of variation of $R F$ over the time period of interest $\mathrm{T}$.

RDe:

$$
P_{D}=\frac{1}{R} \sum_{R} C V_{T}(R D e)=\frac{1}{R} \sum_{R} C V_{T}\left(\frac{D_{A L L}-D_{D E L I}}{D_{A L L}}\right)
$$

where $C V_{T}\left(\frac{D_{A L L}-D_{D E L I}}{D_{A L L}}\right)=$ temporal coefficient of variation (ratio of standard deviation to mean) of the RDe over the time period of interest $\mathrm{T}$ (variability from time to time over the period $\mathrm{T}$ ).

When the concerned delivery parameter is the available pressure head at hydrant, the dependability corresponds to the hydraulic reliability at hydrants, as defined by the Eq. 4 .

As for the Equity indicator, it refers to the spatial uniformity of the irrigation delivery conditions. When the concerned delivery parameter is the irrigation volume, the equity is expressed as the degree of spatial variability of the $R V$ that occurs over the region of interest, $R$, and is expressed by the following relationship:

$$
P_{E}=\frac{1}{T} \sum_{T} C V_{R}(R V)=\frac{1}{T} \sum_{T} C V_{R}\left(\frac{V_{D E L I}-V_{R E Q}}{V_{R E Q}}\right)
$$

where $C V_{R}\left(\frac{V_{D E L I}-V_{R E Q}}{V_{R E Q}}\right)=$ spatial coefficient of variation of the $R V$ over the region of interest $\mathrm{R}$ (variability from point to point over the region).

Likewise the dependability, when the concerned delivery parameter is the timeliness of irrigation, the equity may be expressed in terms of $R F$ or of $R D e$ by the following relationships:

$R F$ :

$$
P_{E}=\frac{1}{T} \sum_{T} C V_{R}(R F)=\frac{1}{T} \sum_{T} C V_{R}\left(\frac{F_{R E Q}-F_{D E L I}}{F_{R E Q}}\right)
$$

where $C V_{R}\left(\frac{F_{R E Q}-F_{D E L I}}{F_{R E Q}}\right)=$ spatial coefficient of variation of the $R F$ over the region of interest R.

RDe:

$$
P_{E}=\frac{1}{T} \sum_{T} C V_{R}(R D e)=\frac{1}{T} \sum_{T} C V_{R}\left(\frac{D_{A L L}-D_{D E L I}}{D_{A L L}}\right)
$$


where $C V_{R}\left(\frac{D_{A L L}-D_{D E L I}}{D_{A L L}}\right)=$ spatial coefficient of variation of the $R D e$ over the region of interest R.

When the concerned delivery parameter is the available pressure head at hydrant, the equity corresponds to the spatial variability of the RPD or of RPDS and thus is expressed either by the relationships 18 or 19 .

RPD:

$$
P_{E}=\frac{1}{T} \sum_{T} C V_{R}(R P D)=\frac{1}{T} \sum_{T} C V_{R}\left(\frac{H_{D E L I}-H_{R E Q}}{H_{R E Q}}\right)
$$

where $C V_{R}\left(\frac{H_{D E L I}-H_{R E Q}}{H_{R E Q}}\right)=$ spatial coefficient of variation of the $R P D$ over the region of interest R.

RPDS:

$$
P_{E}=\frac{1}{T} \sum_{T} C V_{R}(R P D S)=\frac{1}{T} \sum_{T} C V_{R}\left(R P D_{A V E}-0.5 * R P D_{R A N G E}\right)
$$

where $C V_{R}\left(R P D_{A V E}-0.5 * R P D_{R A N G E}\right)=$ spatial coefficient of variation of the RPDS over the region of interest $R$.

Once performance indicators are conceived and defined on the basis of measurable variables, ranking the state of a system requires the computed or estimated performance values being evaluated with respect to defined reference values. Setting minimum performance levels is therefore relevant to diagnostic analyses and to define the states of the system as satisfactory or unsatisfactory.

Within the present work, a tentative set of reference standard values is proposed in the Table 1 for the above described indicators. The values of performance indicators and the relative performance classes are based on prescriptions provided by experienced project personnel (expert opinions) and on the perceived implications of deviation of the performance measures from the reference values identified as satisfactory.

\begin{tabular}{|c|c|c|c|}
\hline \multirow{2}{*}{ MEASURE } & \multicolumn{3}{|c|}{ PERFORMANCE CLASSES } \\
\cline { 2 - 4 } & GOOD & FAIR & POOR \\
\hline RPD & $\geq 0.0$ & $-0.3--0.1$ & $<-0.3$ \\
\hline RPDS & $\geq 0.0$ & $-0.1--0.2$ & $<-0.2$ \\
\hline RV & $-0.1-0.00$ & $-0.3--0.1$ & $<-0.3 ;>0.0$ \\
\hline RF & $\geq 0.0$ & $-0.2-0.0$ & $<-0.2$ \\
\hline RDe & $>0.0$ & $-0.2-0.1$ & $<0.7$ \\
\hline Reliability & $\geq 0.8$ & $0.8-0.7$ & $>1.00$ \\
\hline Dependability & $0.0-0.4$ & $0.4-1.00$ & $>1.00$ \\
\hline Equity & $0.0-0.4$ & $0.4-1.00$ & \\
\hline
\end{tabular}

Table 1. Tentative reference standards for performance assessment 


\section{Description of the study area}

The proposed methodology for operational and performance analysis of pressurized delivery networks was applied to two district delivery networks of an existing irrigation scheme located in southern Italy that is in urgent need of modernization due to its poor performance in terms of water delivery to farmers.

The Sinistra Bradano irrigation scheme (Fig. 4) is located in the western part of the province of Taranto and covers a total topographic area of 9,651 ha. The system is divided into 10 operational districts, ranging in size from a minimum of 353 ha to a maximum 1,675 ha. Each district is subdivided into sectors consisting of a grouped number of farms. The water source is a storage reservoir located on the Bradano River in the nearby region of Basilicata, with a total capacity of $70 \mathrm{Mm}^{3}$, out of which $35 \mathrm{Mm}^{3}$ are usually available for irrigation of the Sinistra Bradano system. The distribution of water to farms is managed by a local Water Users Organization (WUO) and usually starts by late April and ends by late October. The distribution networks are operated on a rotation delivery schedule, with the rotation being fixed for the entire irrigation season with a flow rate of $20 \mathrm{l} \mathrm{s}^{-1} \mathrm{ha}^{-1}$, and 5 hours of delivery to each user and a fixed irrigation interval of 10 days.

Significant conveyance and distribution losses are reported for the study area (INEA 1999), as on average only around $16 \mathrm{Mm}^{3}$ are finally delivered to the cropped fields out of the total volume of $23 \mathrm{Mm}^{3}$ that is diverted from the reservoir. Water is conveyed to the area through a main conveyance canal, from which it is then delivered to farms by means of 10 openbranched district distribution networks. The entire irrigation scheme is subdivided into three operational portions that are commanded by progressive sections of the conveyance canal. The water diversions from the canal to the district distribution networks are controlled by cross-regulators and orifice-type undershot-gate offtakes that are manually operated by the staff of the WUO. The branched delivery networks consist of gravity-fed buried pipelines delivering water to farms with low pressure head.

The pressure at farm hydrants thus originates from the difference in elevation between the offtakes, situated along the conveyance canal, and the lower-elevation irrigated areas. The Sinistra Bradano irrigation system covers an overall cropped and irrigable command area of 8,636 ha. A large reduction in the area serviced by surface water from the WUO and a corresponding strong increase in the area irrigated by groundwater pumping was documented for this system by Zaccaria et al. (2010) on the basis of records provided by the WUO. These changes in the serviced areas are most likely a consequence of the poor conditions of water delivery with respect to farmers' needs. As a result, at present many farmers rely mainly on groundwater pumping for irrigating their crops. Since the available pressure head at hydrants is not sufficient for the proper operation of the on-farm trickle and sprinkler irrigation systems, those farmers who still withdraw water from the delivery network need to use booster pumps downstream of the hydrants to adequately feed their irrigation systems. The actual operation of the distribution system under study, the resulting effects of the operational procedures on crop irrigation management, the low performance in water delivery, and the need for system modernization were documented by previous research works conducted on the study area, all described in details by Zaccaria et al. (2010).

For the purposes of the present study, the inconsistency between the water delivery schedule currently enforced by the WUO and the crops' requirements in terms of 
irrigation volumes can be inferred from the data presented in Table 2, where comparisons are made between required and delivered volumes and timings of irrigations during the 10-day peak demand period of the 2009 season for the main crops grown in the study area. The required irrigation volumes and timings, as well as the maximum allowed delay (days) for avoiding yield reductions higher than $10 \%$ of the maximum achievable yield, were estimated through simulations run by the HydroGEN model and by a daily soilwater balance algorithm implemented in Excel worksheet, whereas the actual deliveries were retrieved from records provided by the WUO. Based on the values reported in Table 2 it can be inferred that the actual water deliveries are not matching the irrigation demand of most of the crops grown in the area. The values of the Relative Volume (RV) show that in most of the cases the volumes delivered are excessive with respect to the estimated requirements.

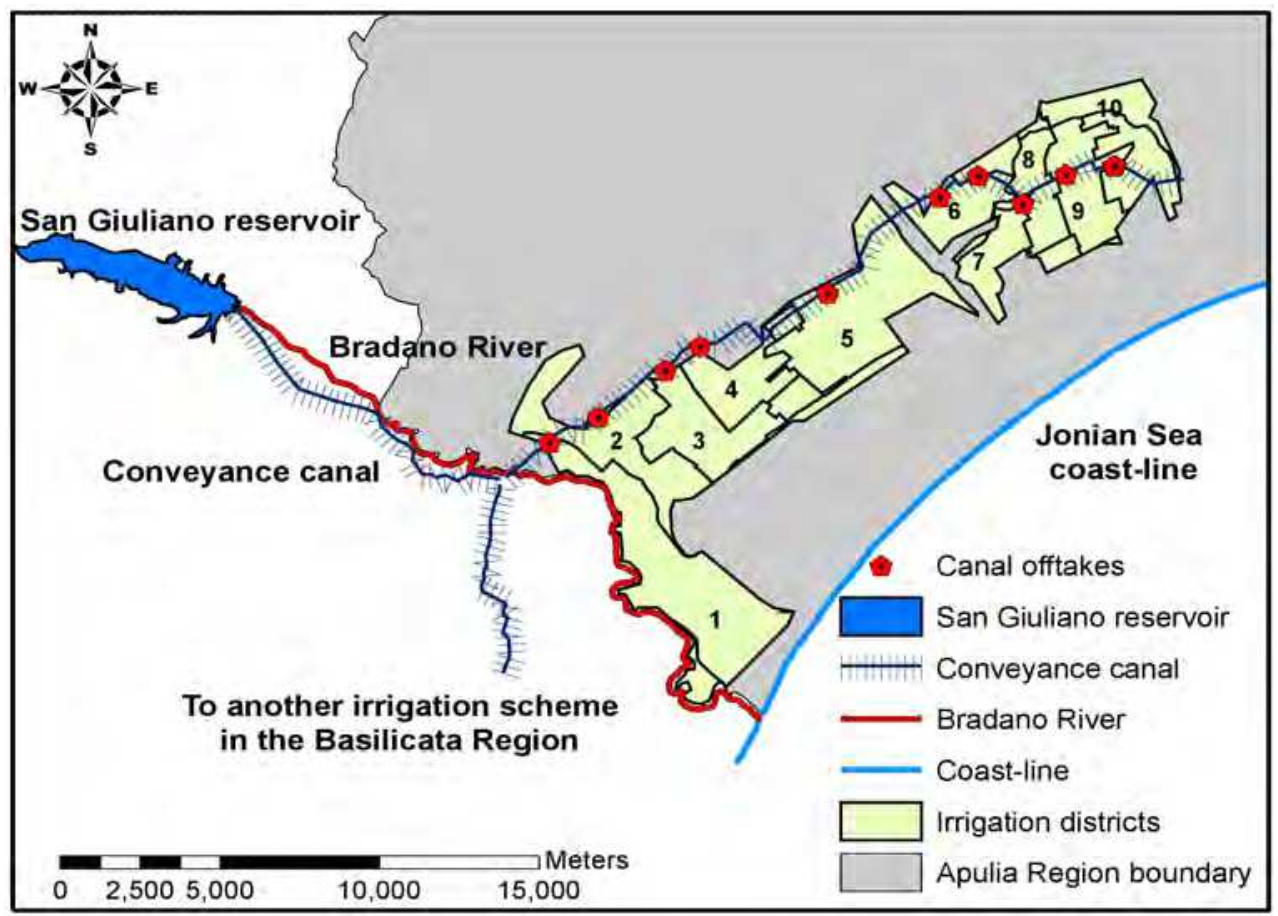

Fig. 4. Overview of the Sinistra Bradano irrigation system.

Only for mature wine grapes and vegetables the delivered volumes are not sufficient to fulfil the irrigation requirements during the peak period. The values of the Relative Frequency, RF, reveal that the current delivery schedule is inadequate for all the considered crops, except for mature olive orchards. The crops suffering most for inadequate frequency of deliveries are the vegetables, table grapes and wine grapes. Also, the estimated values of the Relative Delay, RDe, show that several crops under the current delivery schedule receive water with some delays, with respect to the required irrigation timing, that goes way beyond the maximum allowed delay for avoiding yield reduction higher than $10 \%$. In other 
words, olive and fruit orchards, as well as citrus and vegetables, may face yield reductions way higher than $10 \%$ due to inadequate timing of irrigation deliveries.

Within the Sinistra Bradano irrigation system, two district distribution networks, namely the Districts 7 and 10, were considered in the present study for the application of the proposed methodology, in view of their physical and operational features. Both the districts are located within the last operational portion of the Sinistra Bradano system, with the District 7 being at the initial part and the District 10 being located at the last part of this $3^{\text {rd }}$ portion, and thus being supplied by the tail-end section of the main conveyance canal.

\begin{tabular}{|c|c|c|c|c|c|c|c|c|c|c|c|c|c|}
\hline Crop & M TG & Y TG & M WG & Y WG & M O & Y O & \begin{tabular}{|l|} 
M FO \\
\end{tabular} & Y FO & M TG & M C & Y C & Veg & M Alm \\
\hline $\begin{array}{c}\text { Vol }_{\text {REQ }} \\
\left(\mathrm{m}^{3} / \mathrm{ha}\right) \\
\end{array}$ & 320 & 143 & 428 & 141 & 185 & 96 & 230 & 154 & 297 & 274 & 217 & 745 & 215 \\
\hline $\begin{array}{c}F_{\text {REQ }} \\
\text { (days) }\end{array}$ & 4 & 4 & 5 & 4 & 13 & 9 & 6 & 5 & 5 & 8 & 5 & 3 & 6 \\
\hline $\begin{array}{c}\text { Max All. } \\
\text { Del. } \\
\text { (days) }\end{array}$ & 3 & 3 & 3 & 3 & 2 & 2 & 4 & 4 & 4 & 1 & 1 & 2 & 5 \\
\hline $\begin{array}{c}\text { Vol DEL } \\
\left(\mathrm{m}^{3} / \mathrm{ha}\right)\end{array}$ & 360 & 360 & 360 & 360 & 360 & 360 & 360 & 360 & 360 & 360 & 360 & 360 & 360 \\
\hline $\begin{array}{c}\text { FDEL } \\
\text { (days) }\end{array}$ & 10 & 10 & 10 & 10 & 10 & 10 & 10 & 10 & 10 & 10 & 10 & 10 & 10 \\
\hline $\begin{array}{l}\text { De } \\
\text { (days) }\end{array}$ & 2 & 1 & 1 & 1 & 3 & 7 & 7 & 1 & 4 & 4 & 1 & 3 & 5 \\
\hline RV & 0.12 & 1.52 & -0.16 & 1.55 & 0.94 & 2.74 & 0.57 & 1.34 & 0.21 & 0.31 & 0.66 & -0.52 & 0.68 \\
\hline RF & -1.50 & -1.50 & -1.00 & -1.50 & 0.23 & -0.11 & -0.67 & -1.00 & -1.00 & -0.25 & -1.00 & -2.33 & -0.67 \\
\hline RDe & 0.33 & 0.67 & 0.67 & 0.67 & -0.50 & -2.50 & -0.75 & 0.75 & 0.00 & -3.00 & 0.00 & -0.50 & 0.00 \\
\hline
\end{tabular}

Legend: MTG, YTG = mature and young table grapes; MWG, YWG = mature and young wine grapes; MO, YO = mature and young olives; $\mathbf{M F O}, \mathbf{Y F O}=$ mature and young fruit orchards; $\mathbf{M}$ TGc = mature covered table grapes; $\mathbf{M C}, \mathbf{Y C}=$ mature and young citrus; $\mathbf{V e g}=$ vegetables; $\mathbf{M} \mathbf{A l m}=$ mature almonds

Table 2. Estimation of the adequacy of water deliveries in terms of volumes and timings of irrigation for the peak demand period of the 2009 season for the main crops grown in the study area.

The distribution network of District 7 (Fig. 5) serves 326 hydrants, supplying irrigation water to a total irrigable area of 586.6 ha, of which 119.8 ha are cultivated with table grapes, 54.3 ha with olives, 162.3 with citrus, 58.9 with summer vegetables and 2 ha with almonds. At the design stage the total command area was subdivided into 20 irrigation sectors, whose size ranged from 20 ha to 36 ha.

The District 10 (Fig. 6) is composed of three sub-areas that are supplied by as many distribution sub-networks originating from three different diversions along the last section of the main canal, namely the Diversion 7 (D7), 8-North (D8-N) and 8-South (D8-S). The subnetwork D7 supplies water to 129 hydrants, serving a total irrigable area of 252.6 ha, out of which 198.5 ha are cultivated with citrus, 20.3 with table grapes, 19.6 ha with vegetables, 10.5 ha of olives, and 3 ha with orchards. The sub-network D8-N supplies water to 161 hydrants and serves an overall irrigable area of 661.2 ha, out of which 69.8 ha are cultivated with table grapes, 347.6 ha with vegetables and 4.9 ha with olives. The total irrigable area served by the sub-network D8-S is 445 ha, out of which 81.3 ha are cultivated with table grapes, 230.5 ha with citrus, 42.6 ha with olives and 75.5 ha with vegetables, with a total of 133 supplied hydrants. 
All hydrants in both districts are equipped with flow meters and with rubber-ringed flow limiters allowing for a maximum delivery of $10 \mathrm{l} \mathrm{s}^{-1}$ or $20 \mathrm{l} \mathrm{s}^{-1}$, according to the cropped areas supplied downstream. These discharge values were used as nominal flow rates for simulations related to the current state and operation of the distribution networks. In simulating improved operational scenarios the flow rates at hydrants were instead set according to the estimated discharges required by the downstream cropped and irrigated fields.

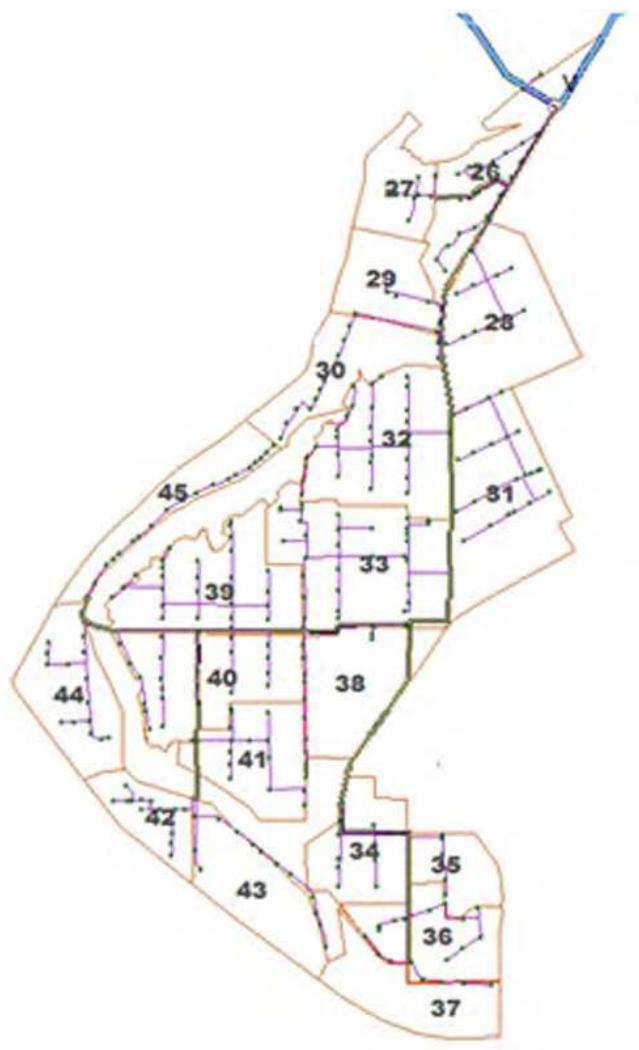

Sinistra Bradano irrigation system

District n.7 - Derivation n.5

\section{Legend}

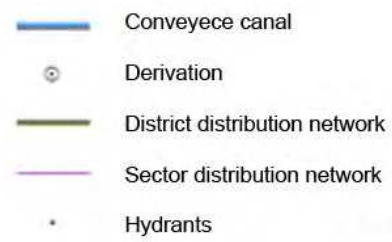

Fig. 5. Overview of District 7 of the Sinistra Bradano irrigation system.

\section{Application of the proposed methodology to the selected irrigation districts}

A more flexible delivery was considered and simulated as alternative schedule to the fix rotation currently enforced in both the irrigation Districts 7 and 10 of the Sinistra Bradano irrigation system. The simulations focused on a restricted-demand delivery to be implemented in both districts to allow for more flexibility to farmers for better managing irrigation on their crops. The feasibility and performance achievable under this alternative delivery schedule were analyzed vis-à-vis with the physical features and constraints of the existing distribution networks. 


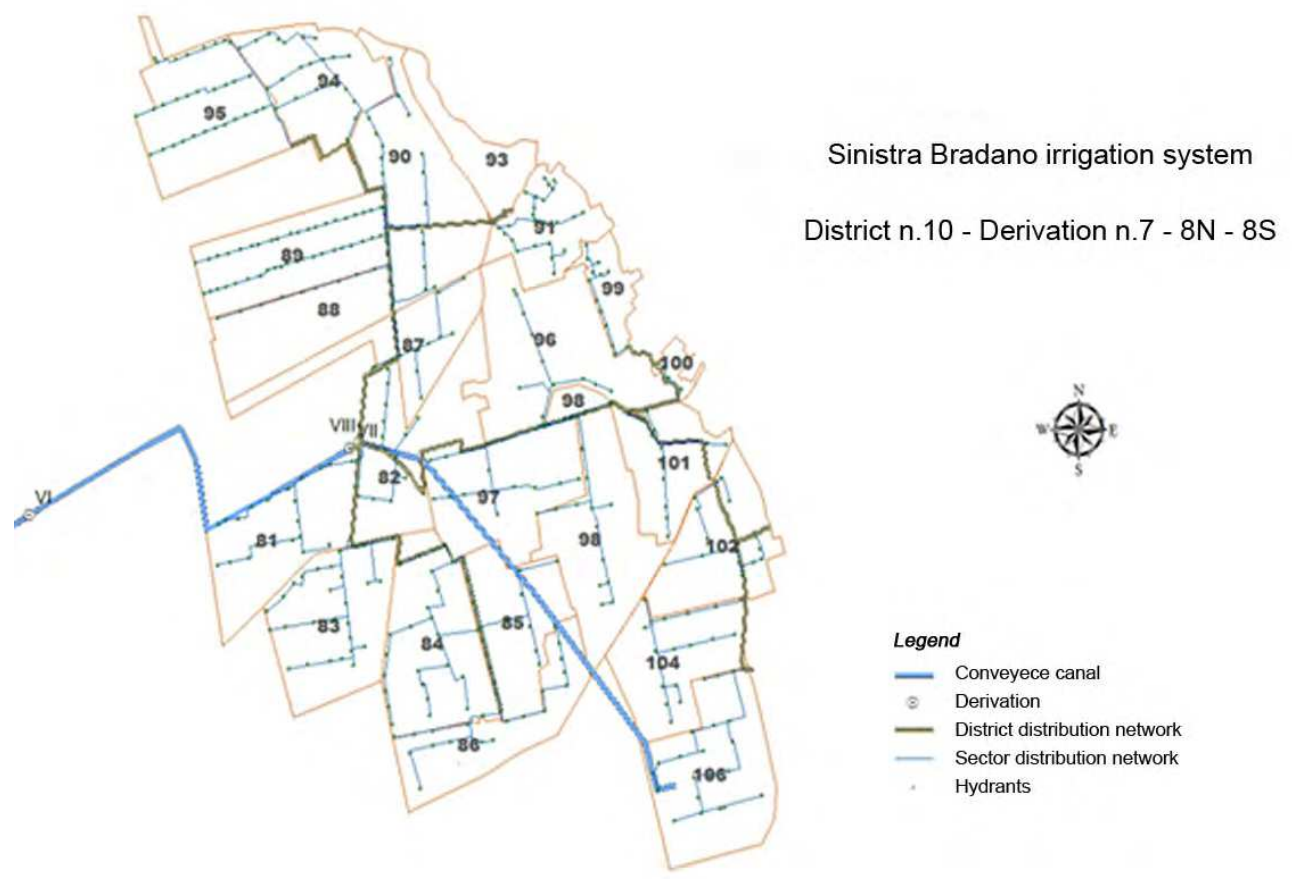

Fig. 6. Overview of the District n. 10 of the Sinistra Bradano irrigation system.

For both the districts, applying the Hydro-GEN model to the cropped areas commanded by the existing distribution networks allowed simulating the irrigation demand hydrographs and the resulting flow configurations during the 10-day peak demand period. The simulations were conducted by using climatic and crop data referred to the 2009 irrigation season, under the irrigation management scenario of full replenishment of the soil water depleted in the root zone, yielding the 10-day peak demand period as occurring in the interval DOY $197-206$ (July $16^{\text {th }}-25^{\text {th }}$ ). Figure 7 shows the simulated demand hydrographs for both districts during the 10-day peak period.

Under the improved delivery scenarios the simulated demand hydrographs and flow configurations result from assuming the fulfilment of the required deliveries at farm level, i.e. irrigation deliveries were simulated as occurring in compliance with the required volumes and timing estimated by the HydroGEN model. In this way, the simulated deliveries in terms of volumes and frequency would thus occur in an adequate way for proper on-farm irrigation. In other words, the adequacy of the simulated deliveries in terms of volumes and timing was assumed as pre-requisite for evaluating the network performance under the required flow configurations.

The flow hydrographs and the resulting flow configurations generated by the HydroGEN model were then inputted in the COPAM model for simulating the hydraulic behaviour and performance of the networks with respect to the target deliveries. The hydraulic performance was analyzed by using three main indicators, namely the Relative Pressure Deficit, $R P D$, the Hydrant Sensitivity, RPDS, and the Hydrant Reliability, $R$. Also for these 
applications, the Equity of the deliveries in terms of available pressure heads was estimated by using the Eq. 19 .
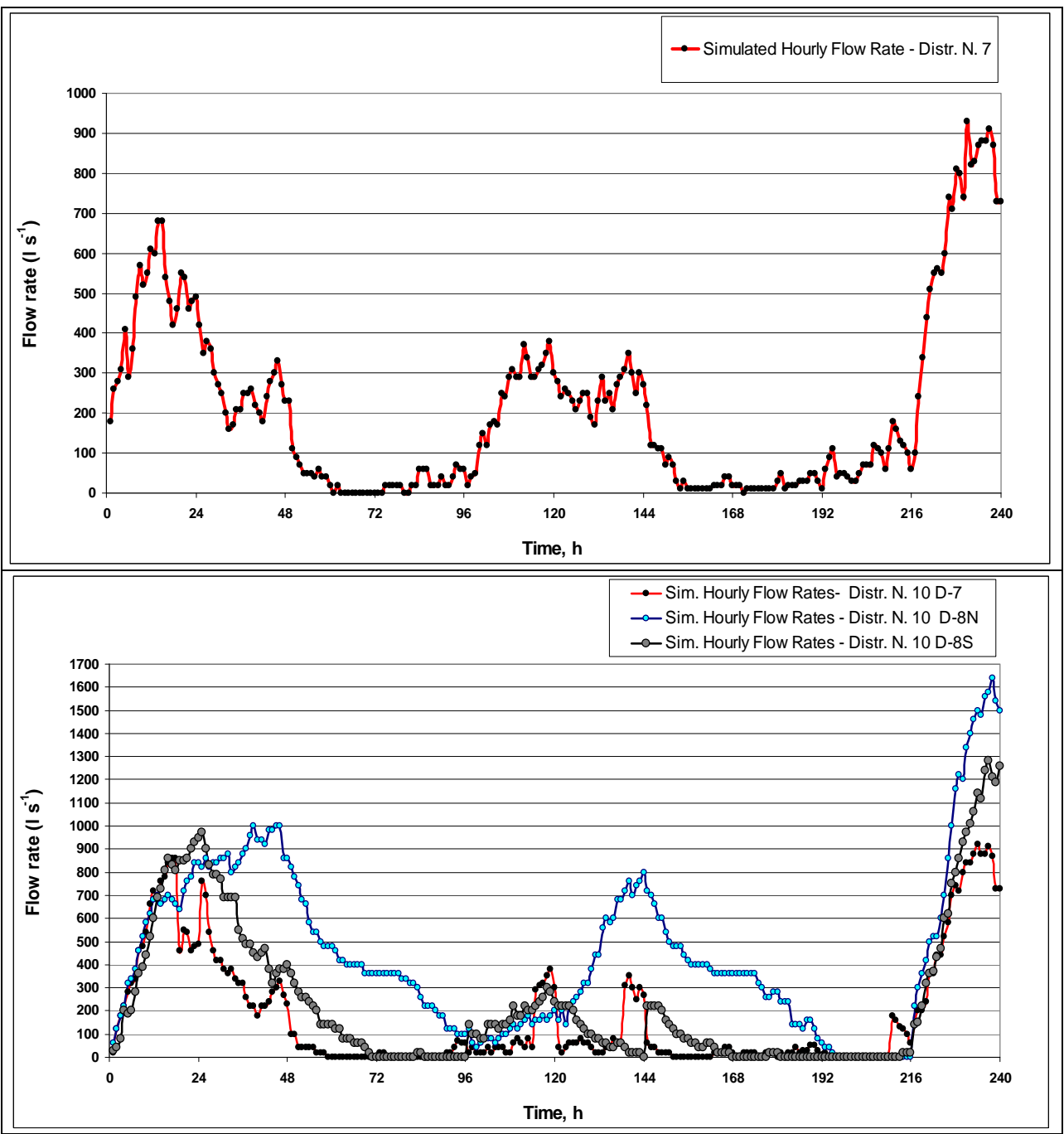

Fig. 7. Simulated hydrographs of hourly flow rates $\left(1 \mathrm{~s}^{-1}\right)$ for the 10-day peak period during the 2009 irrigation season for the delivery networks of District 7 and District 10 of the Sinistra Bradano system.

\section{Results and discussion}

As far as the network of District 7 is concerned, simulations of the restricted demand schedule on the existing delivery network show that poor performance would be achieved in terms of available pressure heads at hydrants, and this would be likely due to physical 
constraints and limitations. As can be seen from Figs. 8 and 9 showing $R P D, R$ and $R P D S$ obtained under this scenario, nearly all hydrants would fall in unsatisfactory state with respect to the necessary pressure head $\left(\mathrm{H}_{\mathrm{REQ}}=20 \mathrm{~m}\right)$ for proper operation of the farm irrigation systems. For nearly all the hydrants the $R P D$ would be way lower than zero, even reaching for several hydrants very negative low peaks (up to values of -4.4). Only for very few hydrants, located in the initial and terminal portions of the network, the minimum required pressure conditions would be satisfied. At the same time, the reliability would yield value of zero for most of the hydrants, revealing unsatisfactory states, and thus insufficient pressure heads on most of the times that the hydrants would be accessed and operated by farmers. As for the hydrant sensitivity, from the Fig. 9 it can be easily inferred that most of the hydrants have very negative value of the RPDS. Figure 9 reveals either the occurrence of large fluctuations of the pressure head at hydrants, or the relative position of the minimum values of RPD being below the zero-line, which represents the adequacy of delivery expressed in terms of pressure head.

Several physical improvements, and their effects on the hydraulic behavior of the distribution network, were simulated by using the available modeling tools in the sequence indicated in Fig. 1. In this set of simulations, a satisfactory performance was found to be achieved as a result of the following physical measures:

1. replacement of the flow limiters at all the hydrants, with the aim of reducing the maximum flow rate that can be withdrawn by users to $10 \mathrm{l} \mathrm{s}^{-1}$ and thus reducing the occurrence of peak flows in the distribution network;

2. installation of a flow limiter at the upstream end of the district network, in order to limit the peak flow to a maximum of $500 \mathrm{~s}^{-1}$ to ensure adequate delivery conditions at hydrants;

3. increase of the total piezometric elevation at the upstream end of the network from the current value of $42 \mathrm{~m}$ to $82 \mathrm{~m}$ a. s. 1., for ensuring enough pressure head at all hydrants under the different configurations of hydrants in simultaneous operation.

Figures 10 and 11 show that, after implementing this set of physical improvements, the distribution network of District 7 would be capable of satisfying the minimum delivery conditions necessary for proper operation of farm irrigation and allow adequate and flexible crop irrigation management to farmers. Under the flexible delivery scenario and with the improved network, the RPD for most of the hydrants would be greater than zero, meaning that the available pressure head would be higher than the minimum required.

Only a few hydrants, corresponding to the numbers from 98 to 107, would have RPD values lower than -0.4 with low peaks up to -1.32 , denoting serious pressure deficits. These hydrants would thus not be capable of satisfying the required pressure head conditions, even if the piezometric head at the inlet of the network is further increased up to $106 \mathrm{~m}$. This is most likely due to the disadvantageous locations of these hydrants in combination with the network layout and pipe size configurations that would cause high friction losses, and make these few hydrants perform unsatisfactorily under most of the flow configurations. This aspect can also be noticed from the estimated reliability of hydrants under the simulated operation of the modernized network, which is reported in Fig. 10. For the majority of hydrants the reliability would reach values of 1.0, apart from a very limited number of hydrants having reliability lower than 0.7 . In four cases, corresponding to the hydrants numbered 94, 104, 106, and 107, the reliability would 
approach values of zero, denoting the occurrence of unsatisfactory states every time these hydrants are operated.

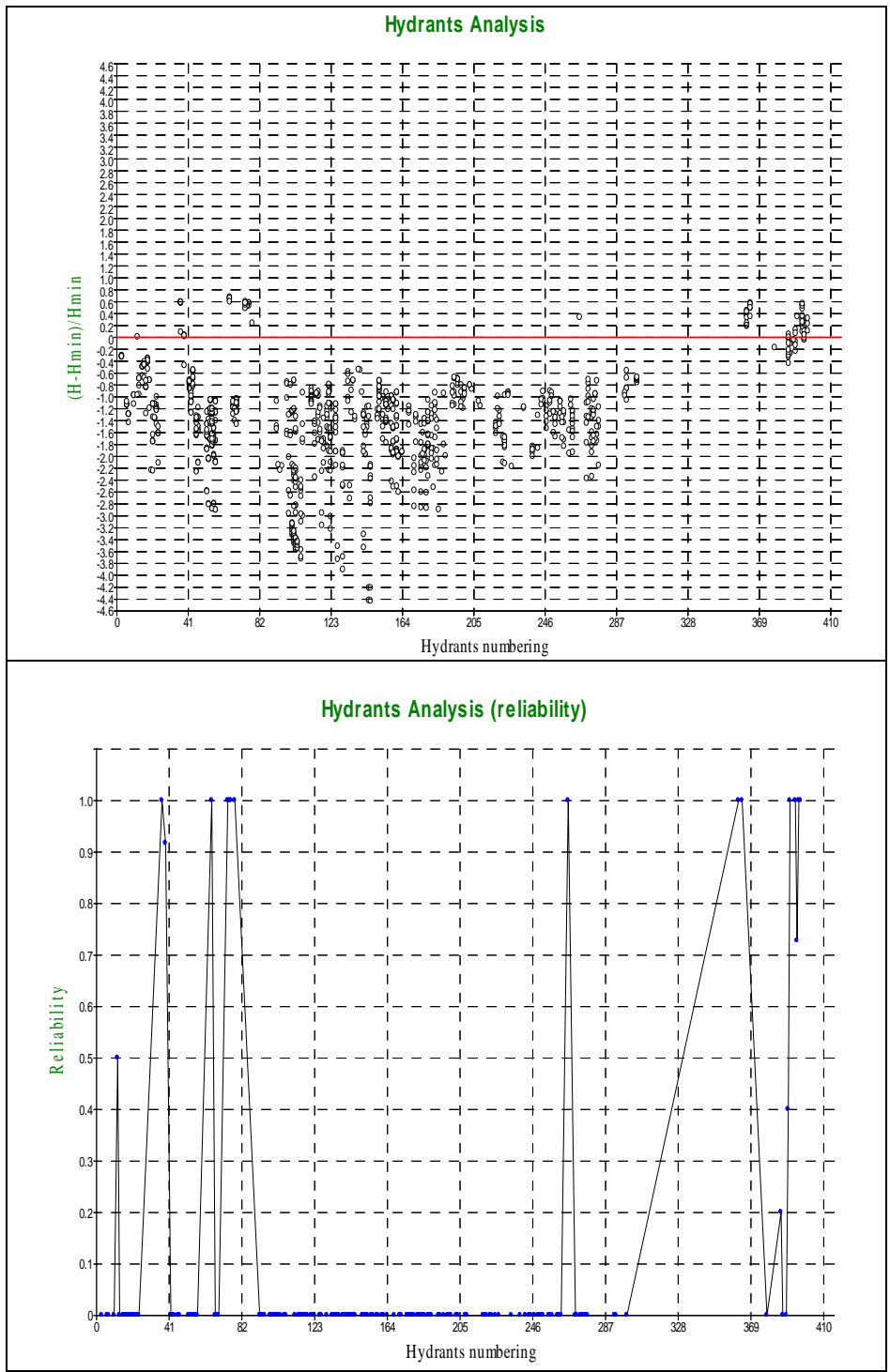

Fig. 8. $R P D$ and $R$ values obtained simulating the restricted demand delivery scenario on the distribution network of District 7 of the Sinistra Bradano system for the 10-day peak period during the 2009 irrigation season. 


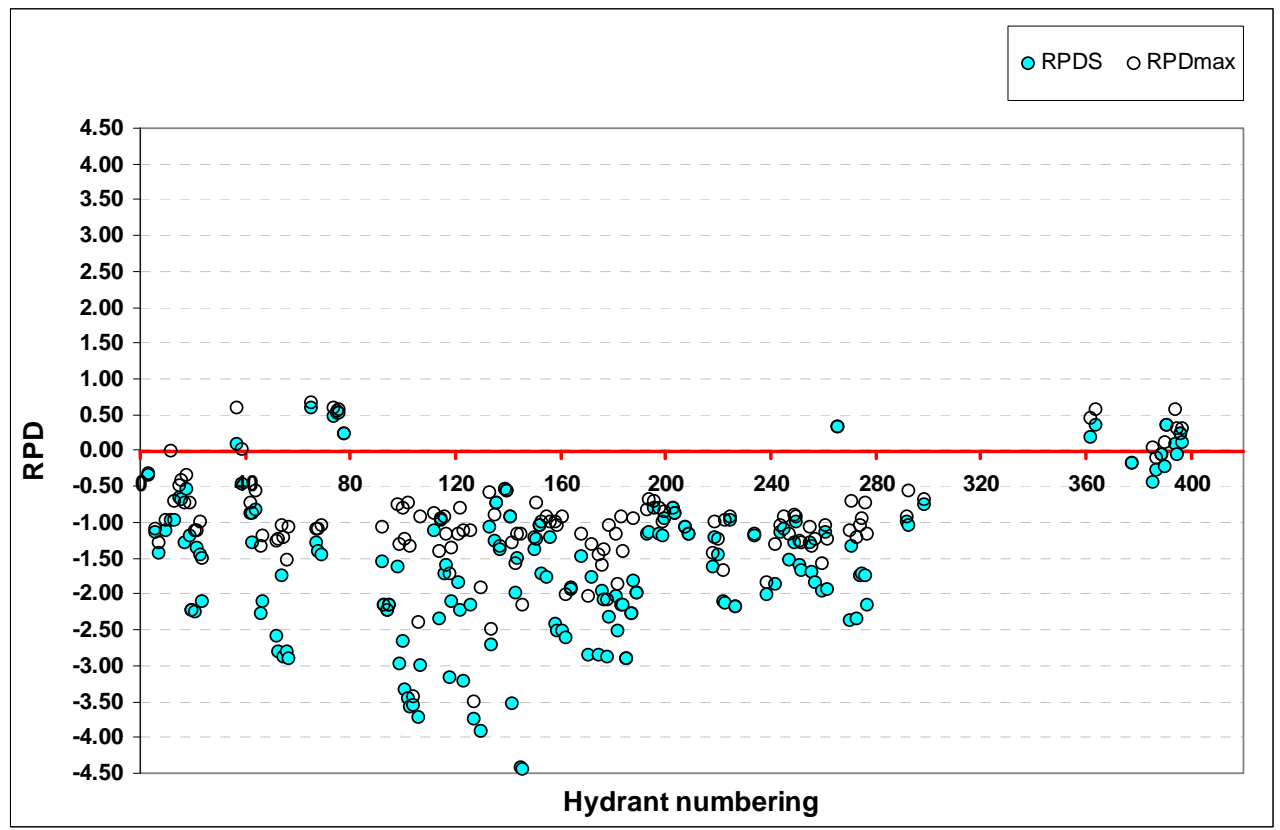

Fig. 9. RPDS values obtained simulating the restricted demand delivery scenario on the distribution network of District 7 for the 10-day peak period during the 2009 irrigation season.

As far as the hydrant sensitivity is concerned, by observing Fig. 11 the improved network seems to work pretty well, as the values of RPDS for nearly all the hydrants, apart from the very few previously identified, would be very close to or higher than zero, revealing that the ranges of fluctuation of the $R P D$ would be small and/or that the minimum $R P D$ values would be mostly above zero.

Under this scenario, the Equity in terms of pressure head was estimated through Eq. 19 and expressed as the spatial variability, $\mathrm{CVr}$, of the RPDS over the district during the peakdemand period. The value of Equity resulted of 1.03, thus revealing that under this improved scenario a large variability of pressure head conditions and of RPDS among hydrants would still exist. Comparing the computed value with the reference standards proposed in Table 1 allowed classifying as "poor" the equity in terms of pressure head in District 7 with the upstream piezometric elevation of $82 \mathrm{~m}$.

By analyzing the hydraulic behavior of the network after the physical improvements it can be inferred that the few hydrants characterized by low performance should be operated separately from the rest of hydrants, with the aim of ensuring adequate performance to the entire distribution network. In other words, these hydrants should be operated during lowpeak demand hours to avoid excessive peak flows in the pipe network and, thus, the high friction losses resulting from limited pipe sizes or limited section capacity. From Fig. 7 showing the demand flow hydrograph simulated for District 7 it can be inferred that low-peak demand flows occur daily before 6 a.m. and after 6 p.m. and, so restrictions in the operation could be set to allow farmers accessing these hydrants within this specific time slots. 


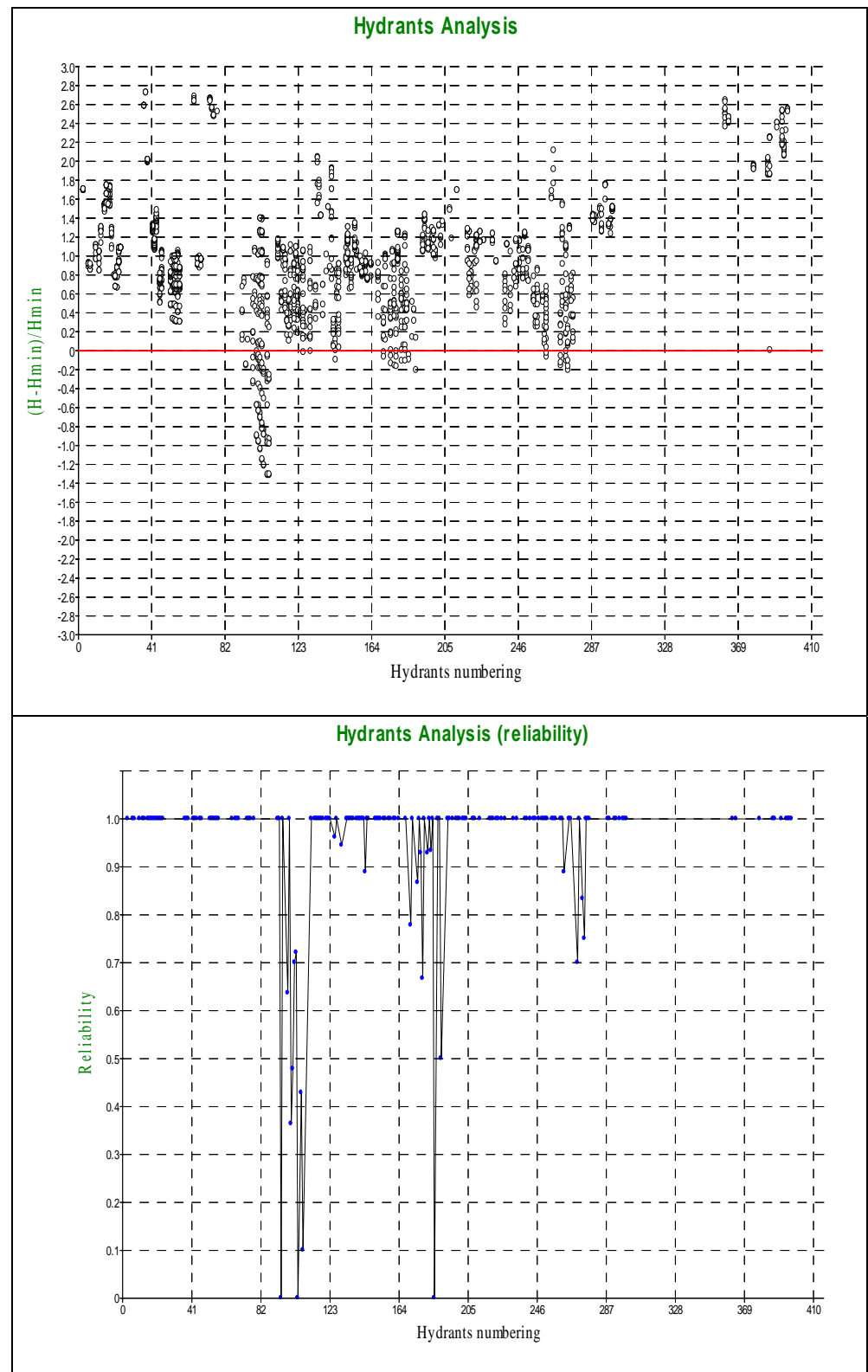

Fig. 10. $R P D$ and $R$ values obtained simulating the restricted demand delivery scenario on the distribution network of District 7 after implementing the physical improvements. 


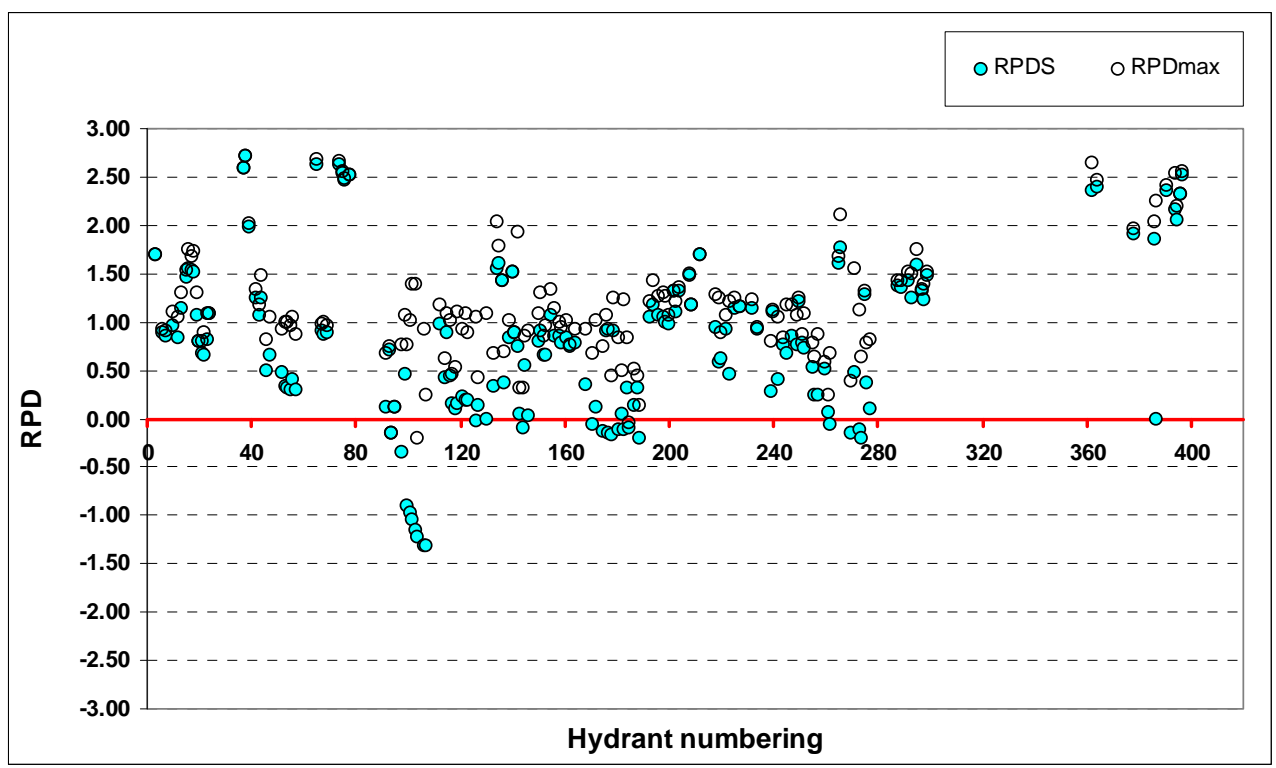

Fig. 11. RPDS values obtained simulating the restricted demand delivery scenario on the distribution network of District 7 after the implementation of the physical improvements.

Further simulation runs show that a complete satisfactory state for all the hydrants under the peak-flow configurations would require an upstream piezometric head of $106 \mathrm{~m}$, as can be noticed from the Figs. 12 and 13 presenting the simulated RPD, $R$ and RPDS achievable under this improvement scenario.

After this further increase to $106 \mathrm{~m}$ a.s.l. the estimation of Equity yielded a value of 0.49 , which enables to classify the Equity under this improvement scenario as "fair," as there is still variability of pressure head conditions and of RPDS among hydrants, but this variability decreased from the scenario with the piezometric elevation of $82 \mathrm{~m}$ a.s.l.

As for the District 10, simulations were run separately for each of the three distribution subnetworks (Diversion 7, D7, Diversion 8 North, D8-N, and Diversion 8 South, D8-S) to evaluate the feasibility of the flexible water delivery schedule and to assess the performance achievable by the existing network under the improved scenarios. Nevertheless, only results related to the sub-networks D8-N and D8-S of District 10, which represent the very tail-ends of the entire irrigation system, are presented in this section.

Simulating the implementation of the restricted demand delivery schedule, the sub-network D8-N as it is in the present state would perform very poorly in terms of pressure head at hydrants. Figures 14 and 15 present the $R P D, R$ and $R P D S$ by the distribution network D8-N under restricted demand schedule. The values of these parameters in the figures clearly show that the network in its current state would not be capable of supplying water by restricted demand schedule with adequate performance, as all the hydrants, except one, would fall in unsatisfactory state with respect to the minimum required pressure head conditions. As a matter of fact, the pressure heads resulting at all hydrants of the network under this delivery scenario would be way lower than that required. 


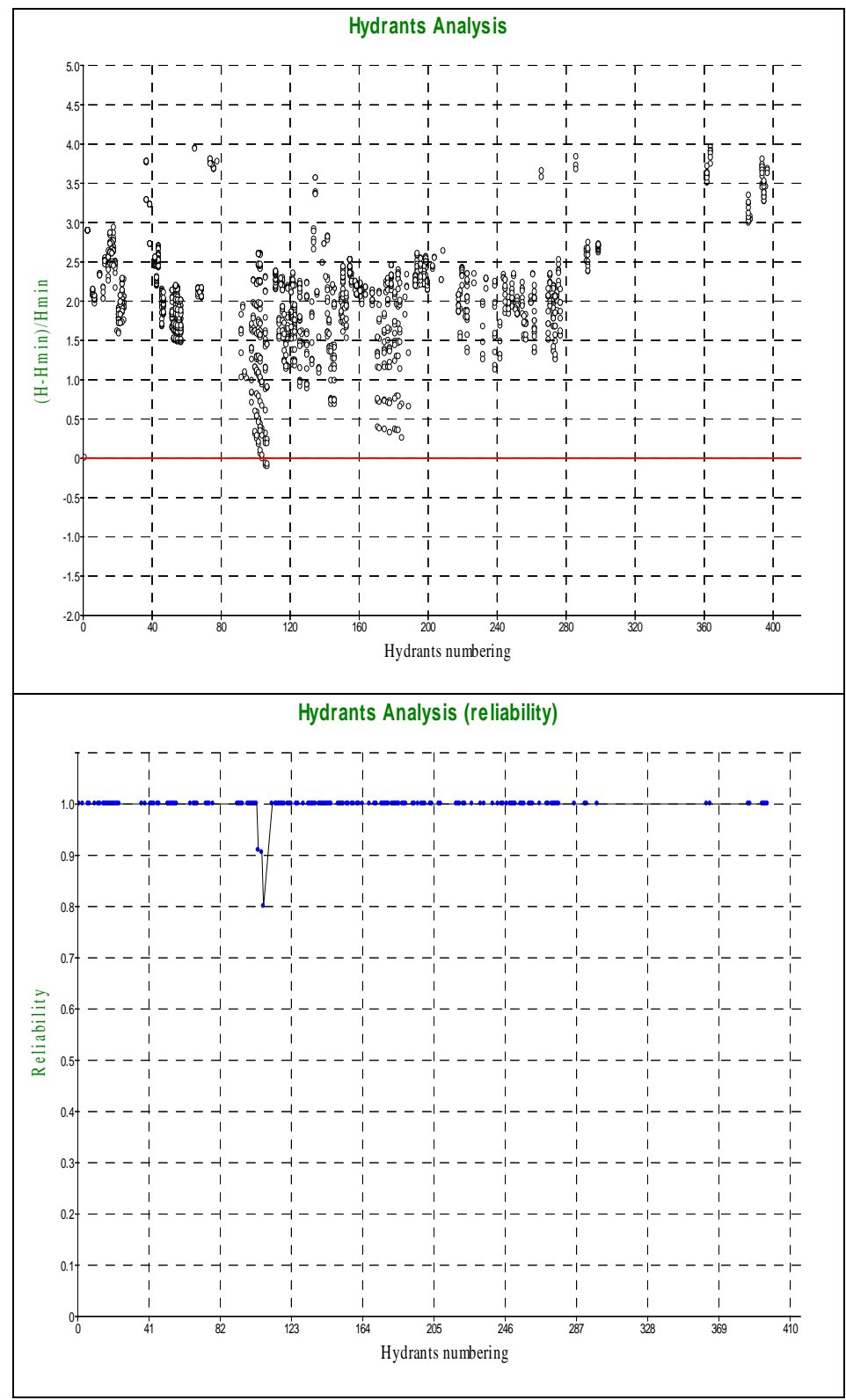

Fig. 12. $R P D$ and $R$ values obtained simulating the restricted demand delivery scenario on the distribution network of District 7 after increasing the total piezometric heat to $\mathrm{H}=106 \mathrm{~m}$ a.s.l. 


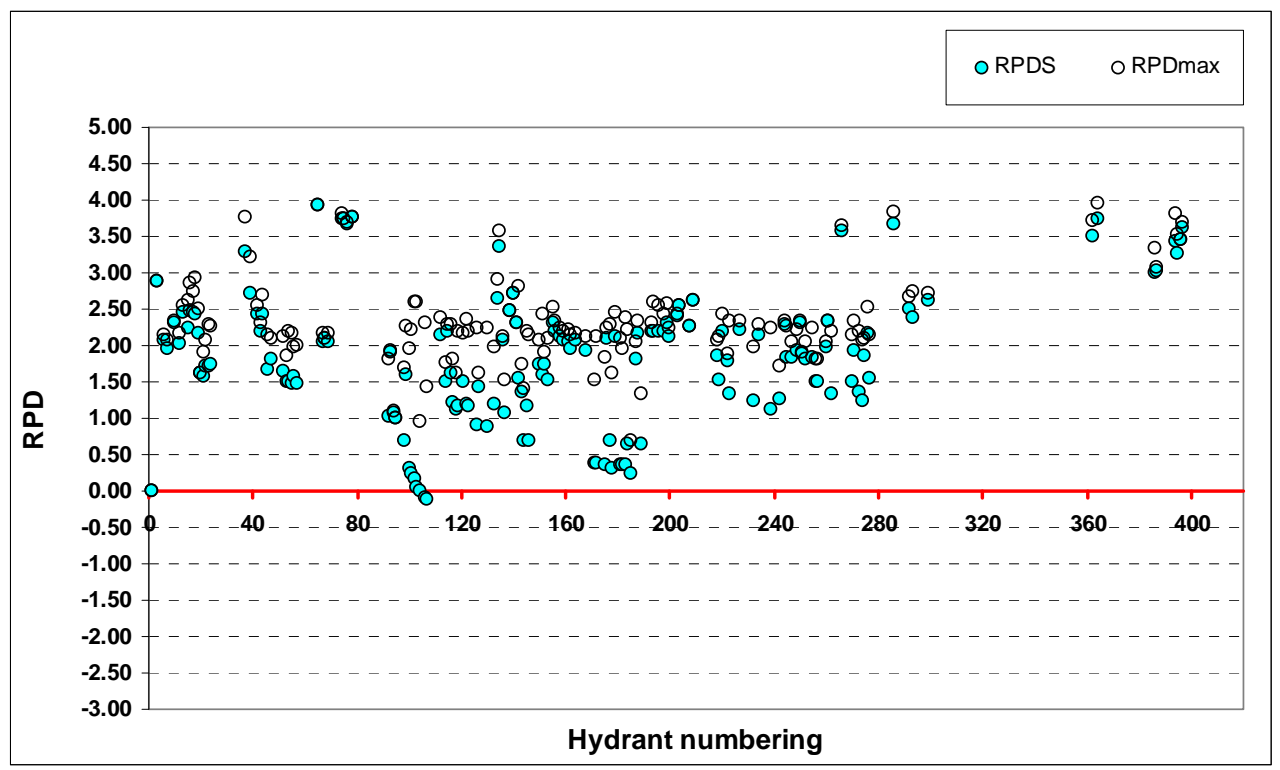

Fig. 13. RPDS values obtained simulating the restricted demand delivery scenario on the distribution network of District 7 after increasing the total piezometric head to $\mathrm{H}=106 \mathrm{~m}$ a.s.l.

The value of the reliability at all hydrants, except for one, would be falling along the zero line, meaning that hydrants' state would be unsatisfactory every time they are put into operation. Figure 15 also shows the occurrence of limited to medium fluctuations of pressure heads at hydrants, but all falling within the negative range.

Further simulations were run also for this sub-network to figure out the effects of physical improvements on its hydraulic behavior, and satisfactory performance would be obtained after implementing the physical changes indicated hereafter:

1. limitation of the flow rate that can be withdrawn by users to $10 \mathrm{l} \mathrm{s}^{-1}$ through the installation of adequate rubber-ringed flow limiters at all hydrants;

2. increase of the total piezometric elevation at the upstream end of the network from the current value of $36 \mathrm{~m}$ a.s.l. to $82 \mathrm{~m}$ a. s. 1. to ensure enough pressure head under the different configurations of hydrants in simultaneous operation.

Figures 16 and 17 present the results of simulations and the level of performance achievable by the sub-network D8-N after the indicated modernization measures. 


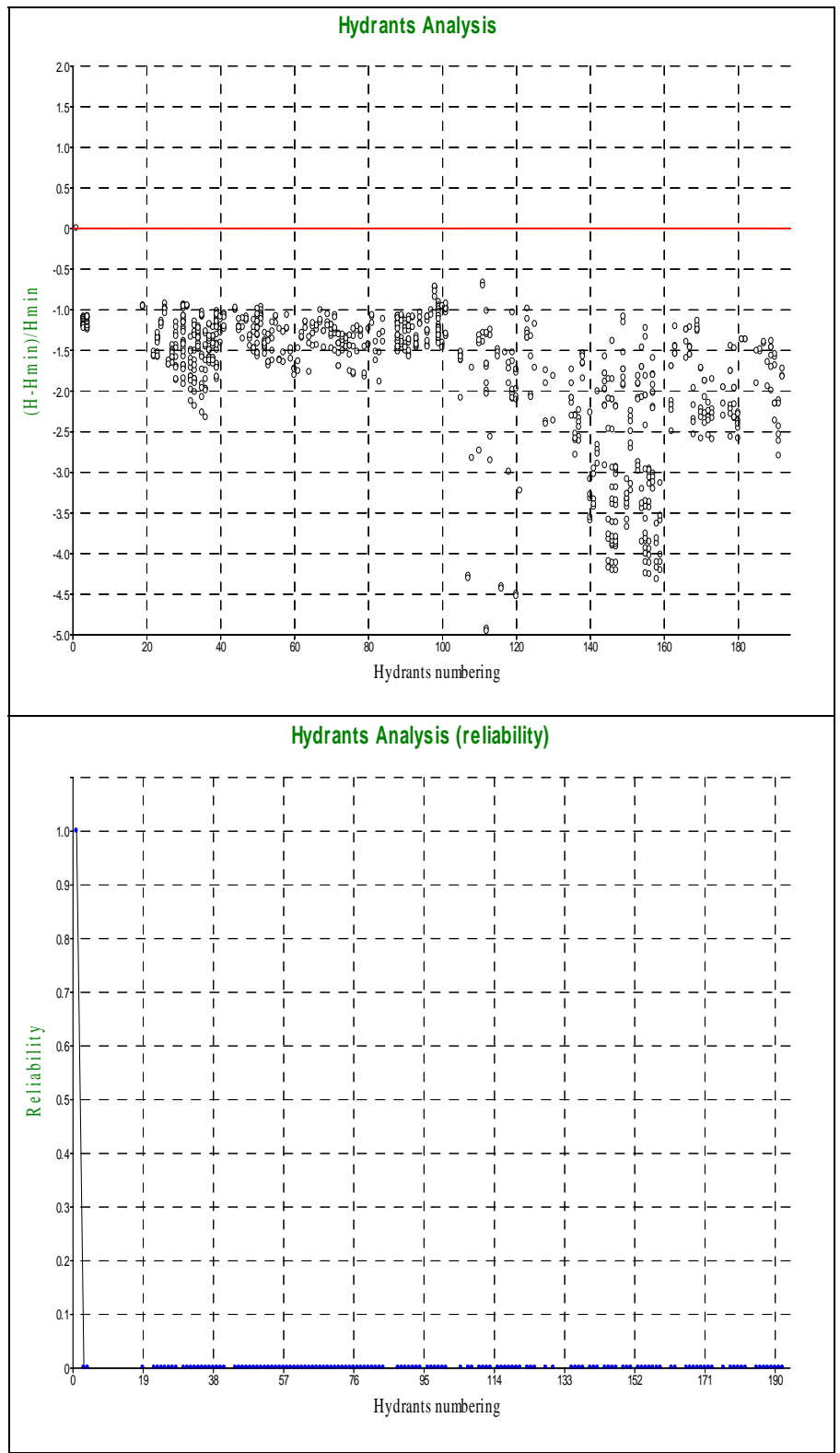

Fig. 14. $R P D$ and $R$ values obtained simulating the restricted demand delivery scenario on the existing distribution network D8-N of District 10 of the Sinistra Bradano system. 


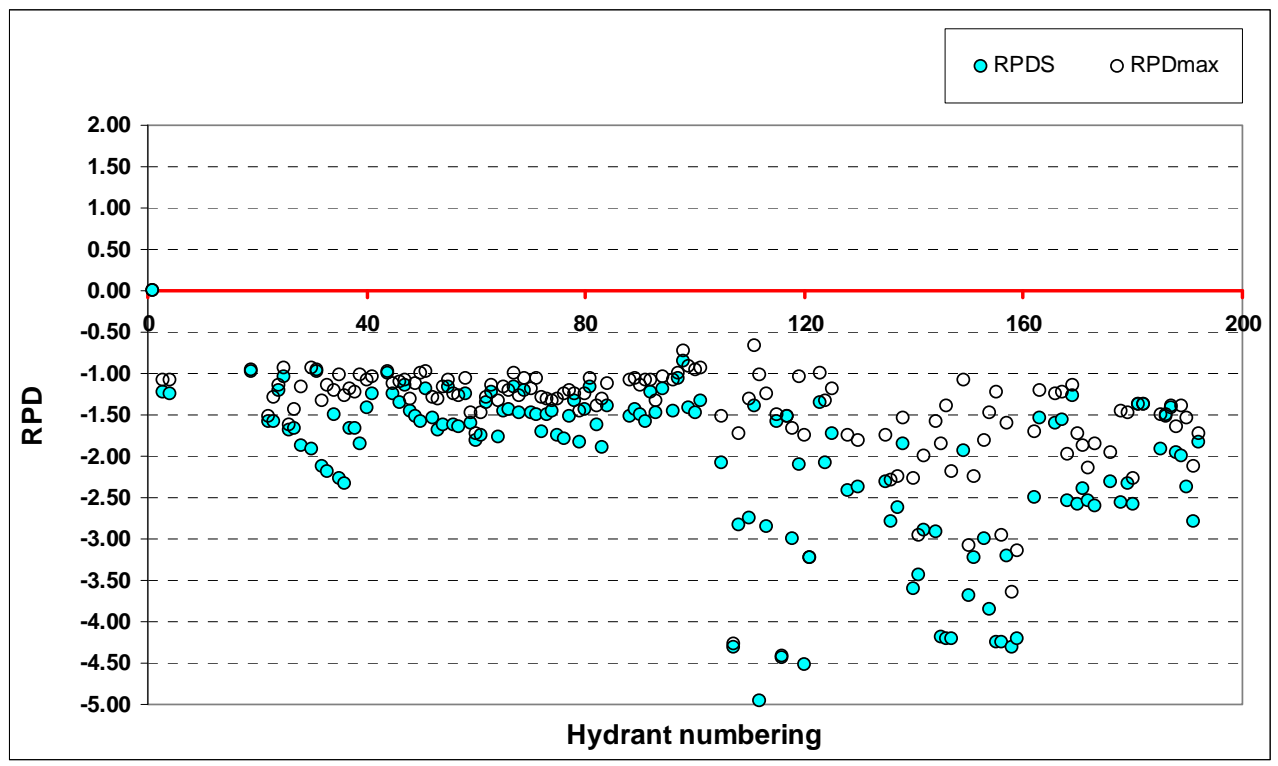

Fig. 15. RPDS values obtained simulating the restricted demand delivery scenario on the distribution network D8-N of District 10.

After the implementation of physical improvements, only a few hydrants, namely those between the numbers 106 and 121 and between 138 and 160, would still fall in unsatisfactory state, due either to their disadvantaged locations or to physical constraints in the upstream pipe sections.

In order to achieve adequate performance in terms of pressure head, it is recommended to allow the operation of these hydrants during low-peak demand hours (6 p.m to 6 a.m) to ensure the adequacy of deliveries in terms of flow rates and pressure heads. After this set of physical improvements the estimation of Equity yielded a value of 2.37, which reveals a very large variability of pressure head conditions and thus a "poor" level of equity among hydrants.

Alternatively, rising up the performance of these groups of hydrants to a satisfactory level, and avoiding, at the same time, the restriction of their operation during peak hours requires increasing the upstream piezometric head up to $140 \mathrm{~m}$. Figures 18 and 19 present the simulated values of $R P D, R$ and $R P D S$ following the above-indicated increase in the piezometric elevation.

From these figures it can be noticed that an upstream piezometric elevation of $140 \mathrm{~m}$ would allow all hydrants performing more than satisfactorily in terms of pressure heads, and that the values of the reliability indicator would be equal to 1 for nearly all hydrants of the network, meaning that the pressure head of delivery would be equal or higher than the minimum required every time the hydrants are operated. 


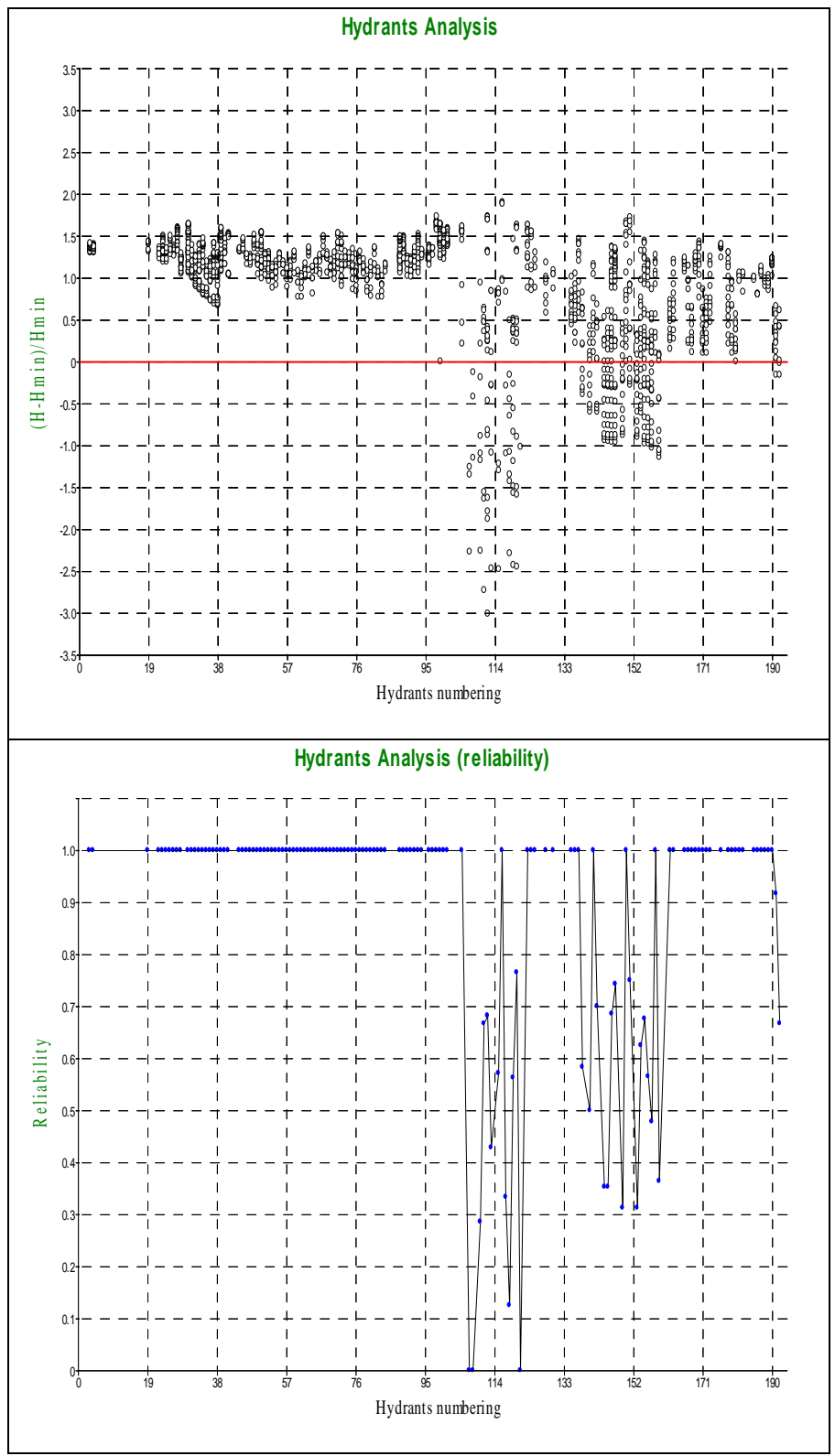

Fig. 16. $R P D$ and $R$ values obtained simulating the restricted demand delivery scenario on the distribution network D8-N after implementing physical improvements. 


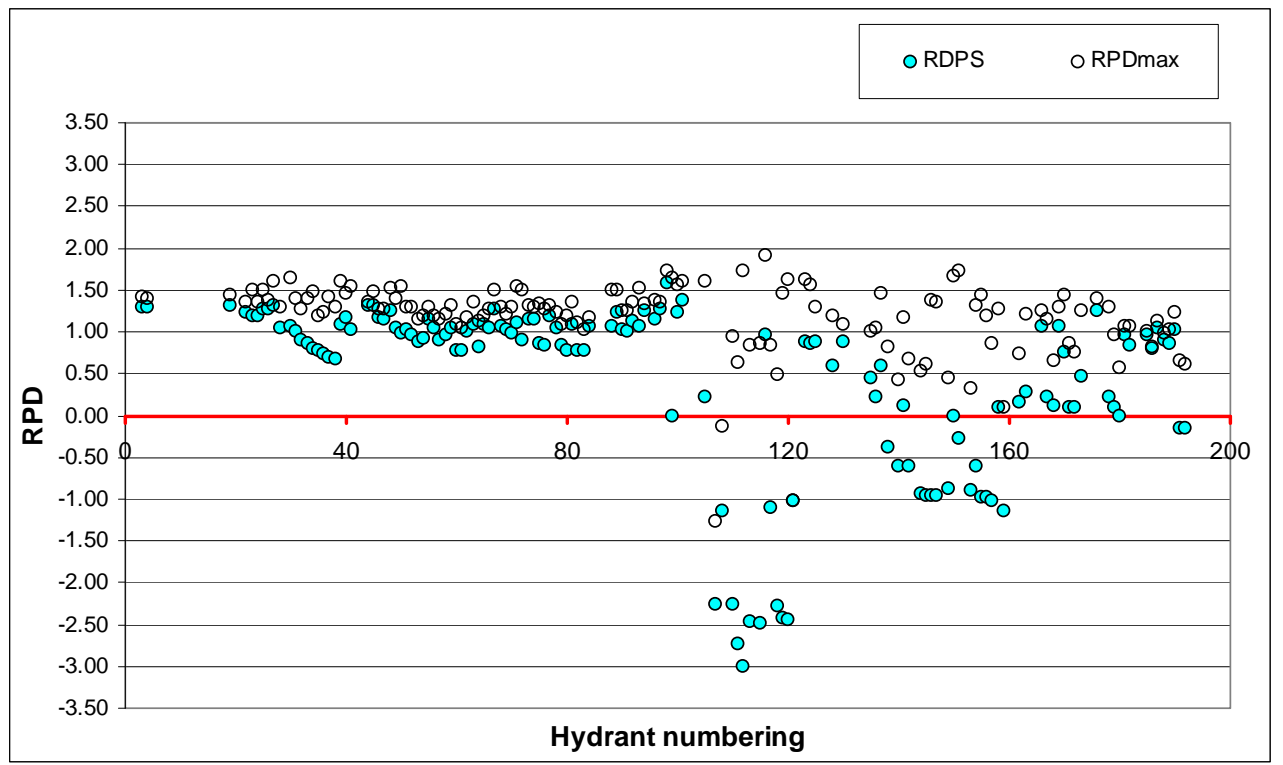

Fig. 17. Values of RPDS obtained simulating the restricted demand delivery scenario on the distribution network D8-N of District 10 after implementing the physical improvements.

Also, the value of RPDS for all hydrants, except for three, would fall in the positive range and for most hydrants would be way higher than zero and also would show quite limited pressure fluctuations. Under this improved scenario, the estimated value of Equity would be of 0.34 , showing a much smaller variability of pressure head conditions among hydrants with respect to the situation with the upstream piezometric elevation of $82 \mathrm{~m}$ a.s.l.

By increasing the upstream piezometric elevation from 82 to $140 \mathrm{~m}$ a.s.l., the equity in terms of pressure conditions at hydrants would also increase from "poor" to "good."

Similar results were obtained simulating the restricted demand delivery on the sub-network D8-S in its current state. Figures 20 and 21 clearly show that the performance achievable by the D8-S network in terms of pressure heads would be very poor, as the values of RPD would be way below the zero line, the values of the reliability would be zero and the value of RPDS would be far below zero for all hydrants.

Similar physical changes as those proposed for the sub-network D8-N are necessary to the sub-network D8-S to make it capable of performing satisfactorily under the restricted demand delivery schedule. Figures 22 and 23 present the simulated values of $R P D, R$ and $R P D S$ after up-grading the network D8-S by means of the following physical measures:

1. limitation of flow rate that can be withdrawn by farmers to $10 \mathrm{l} \mathrm{s}^{-1}$ by installation of adequate rubber-ringed flow limiters at all hydrants;

2. increase of the total piezometric elevation at the upstream end of the network from the current value of $36 \mathrm{~m}$ to $86 \mathrm{~m}$ a.s.l.

From these figures it can be noticed that under the improved scenario only a few hydrants out of the total number, namely the hydrants numbered from 53 to 66 and from 165 to 178, 


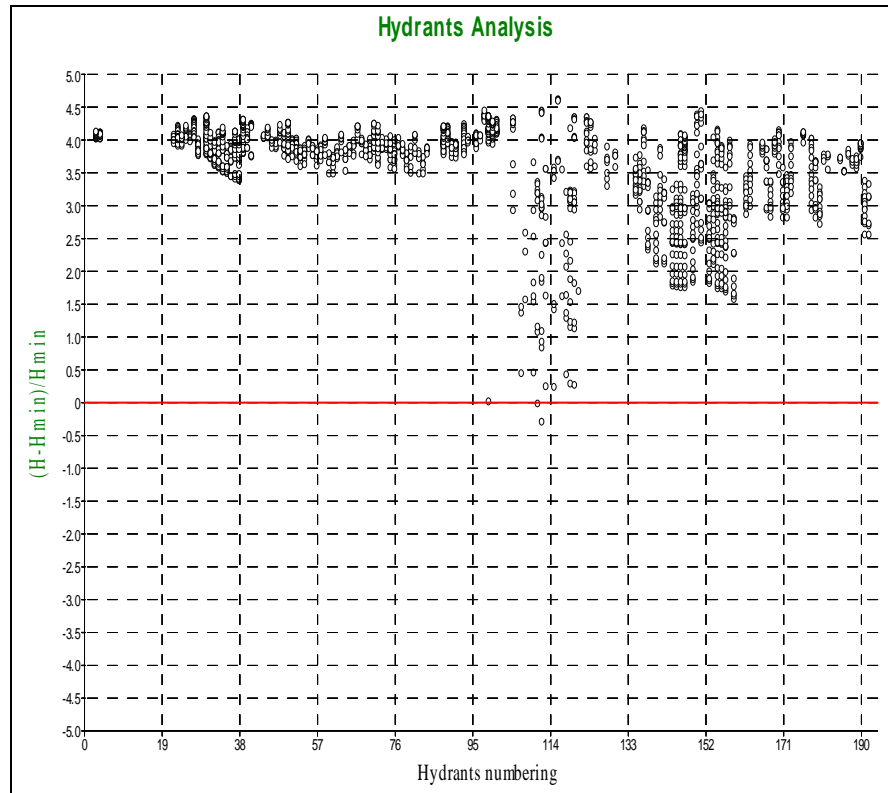

Hydrants Analysis (reliability)

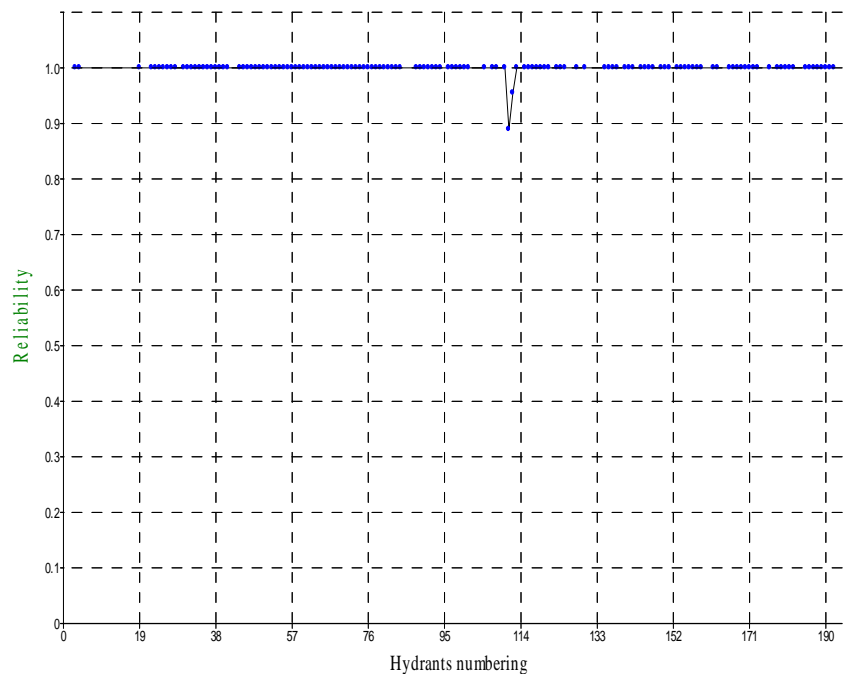

Fig. 18. Values of $R P D$ and $R$ obtained simulating the restricted demand delivery scenario on the distribution network D8-N after increasing the total piezometric heat up to $140 \mathrm{~m}$ a.s.l. 
would not achieve satisfactory performance in terms of pressure heads. Also in this case, it is recommended the access and operation of these groups of hydrants by farmers separately from all the rest, thus only during low-peak demand hours.

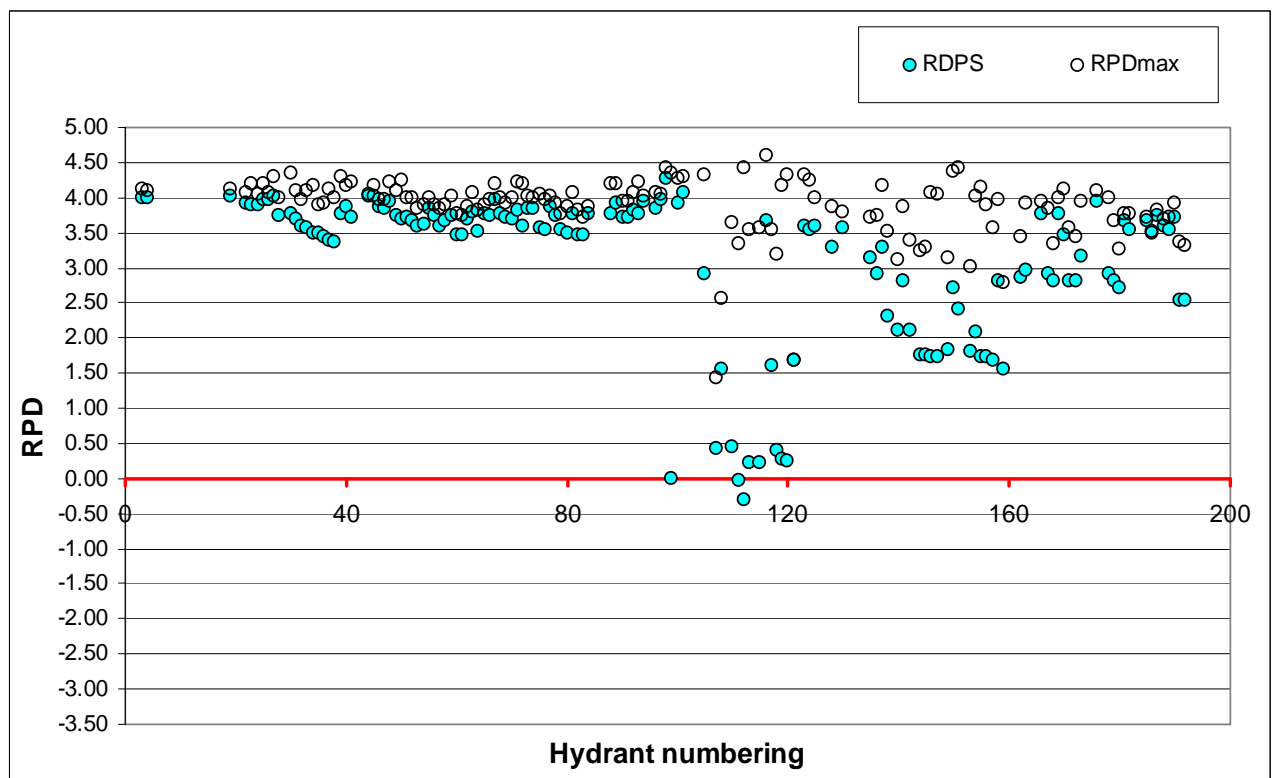

Fig. 19. RPDS values obtained simulating the restricted demand delivery scenario on the distribution network of D8-N after increasing the total piezometric head to $\mathrm{H}=140 \mathrm{~m}$ a.s.l.

The Equity in this case would result as "poor," as the calculated value of 1.74 would reveal large variability in pressure head conditions among hydrants.

Results from simulations show that a further increase of the upstream piezometric head to $126 \mathrm{~m}$ a.s.l. would allow all hydrants of the D8-S network performing satisfactorily with respect to the required pressure head conditions, at any time they are accessed and operated by farmers. Figures 24 and 25 show that, after this further improvement, all the hydrants would achieve adequate or more than adequate performances, and specifically RPD values higher than zero, $R$ values equal or very close to 1 and $R P D S$ values very close or higher than zero.

The estimated value of 0.39 would rank the Equity as "good" in this scenario and would show a strong reduction in the spatial variability of pressure head conditions at hydrant by rising the upstream piezometric head from $86 \mathrm{~m}$ to $126 \mathrm{~m}$ a.s.l.

For both the districts analyzed, physical improvements of the distribution networks entail the increase of the piezometric heads at the upstream ends with the aim of allowing the demand flow configurations and offset all the resulting friction losses, also ensuring adequate water delivery conditions. To address this aspect, a pump system can be designed and sized to operate either at a fix set-point or to modulate the flow rate and pressure head based on the network's characteristic curves under the different flow configurations, and 

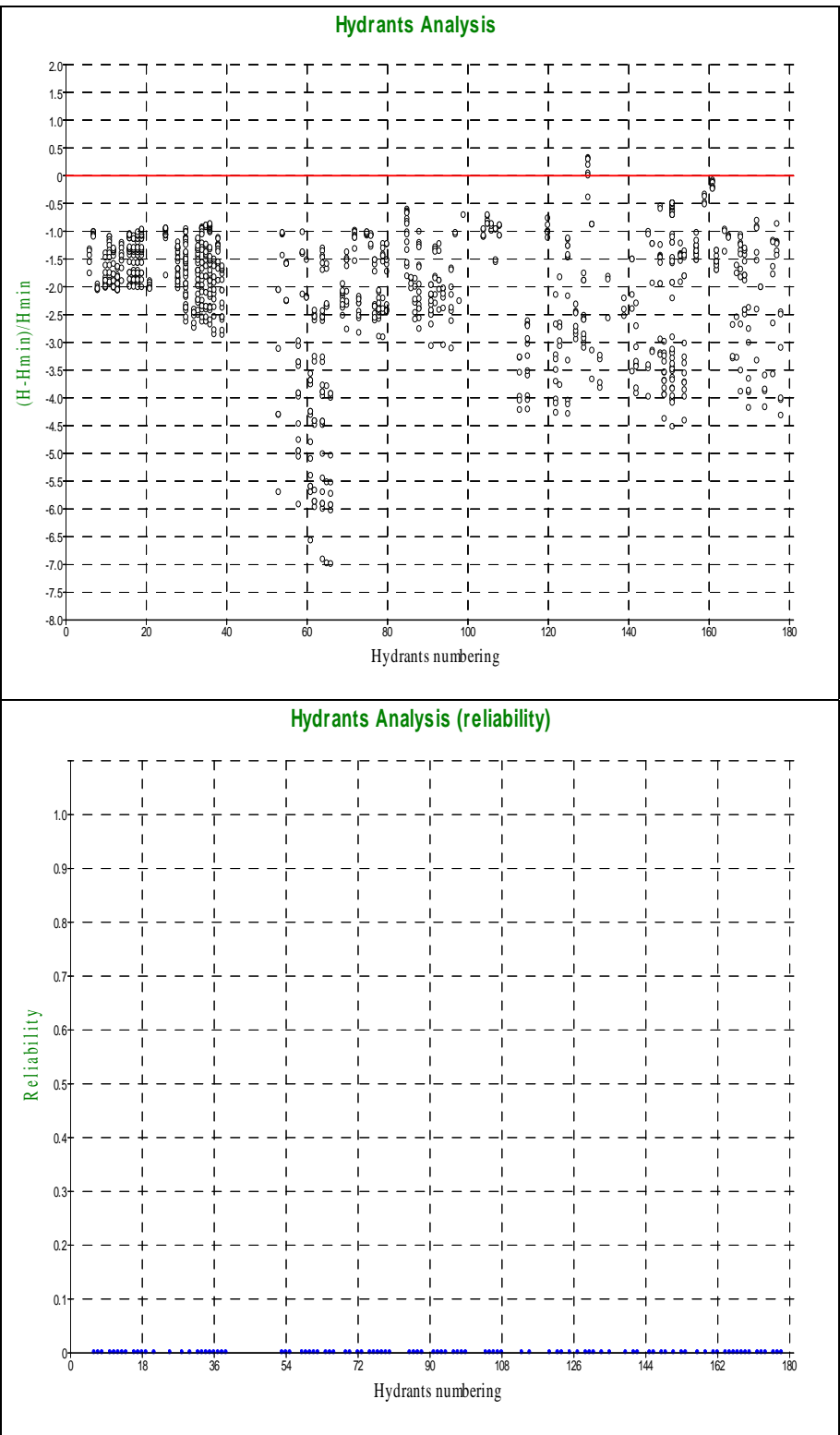

Fig. 20. $R P D$ and $R$ values obtained simulating the restricted demand delivery scenario on the existing distribution network D8-S of District 10 of the Sinistra Bradano system. 
thus according to the downstream flow and pressure requirements. Assuming the operation of both districts by restricted demand, flow regimes in the pipe networks would vary with time based on configurations of hydrants in simultaneous operation. As a result, also friction losses would vary with time and so will also do the total dynamic head (TDH) that is needed at the upstream end of the network to offset head losses and to fulfill the pressure requirements at all the delivery points. Under these conditions, a sound technical solution could be represented by pumping plants capable of adjusting both the discharge and TDH based on downstream requirements, and thus on the basis of system curves resulting from the flow configurations and from the configurations of hydrants in simultaneous operation throughout the distribution network. These technical features can be accomplished by means of variable-speed pumps, in which pump units are equipped with inverters and devices for modulating the speed and operate on the basis of specific hydraulic algorithms.

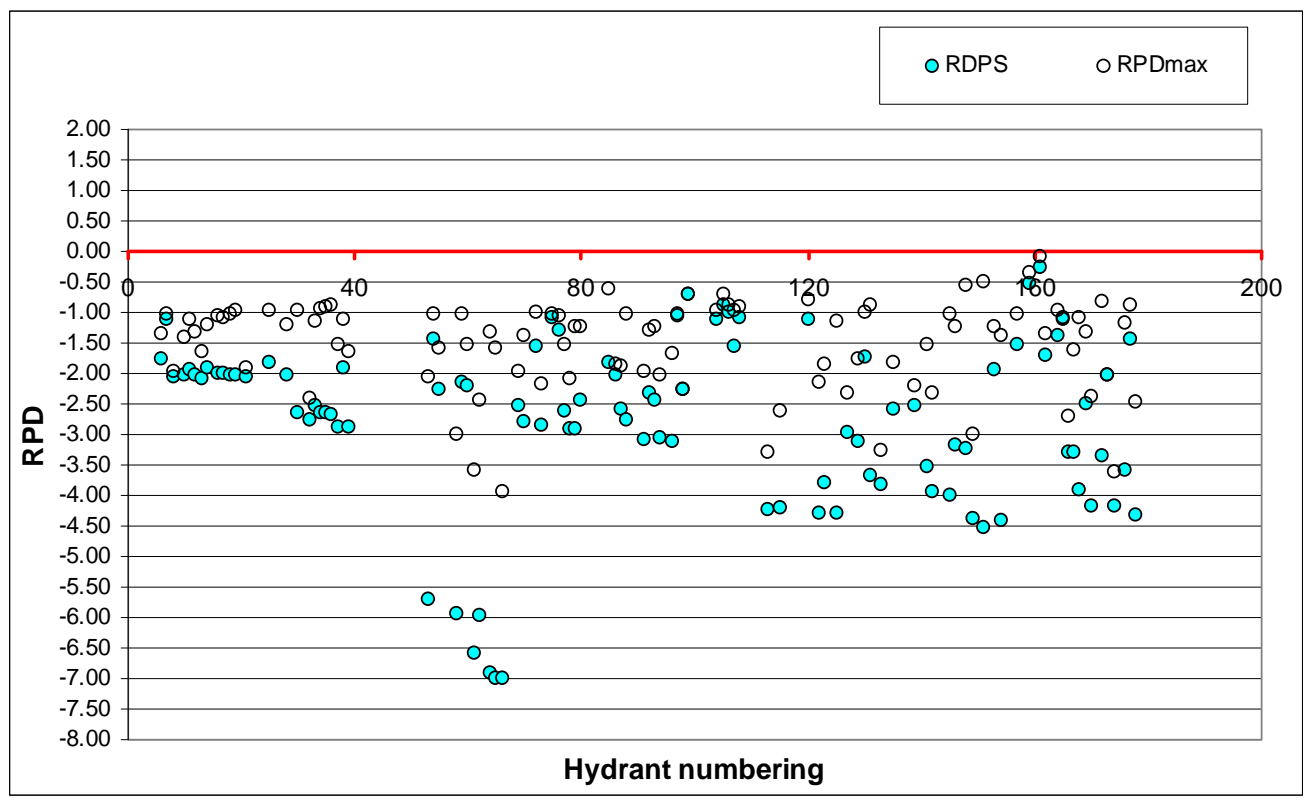

Fig. 21. RPDS values obtained simulating the restricted demand delivery scenario on the distribution network D8-S of District 10. 


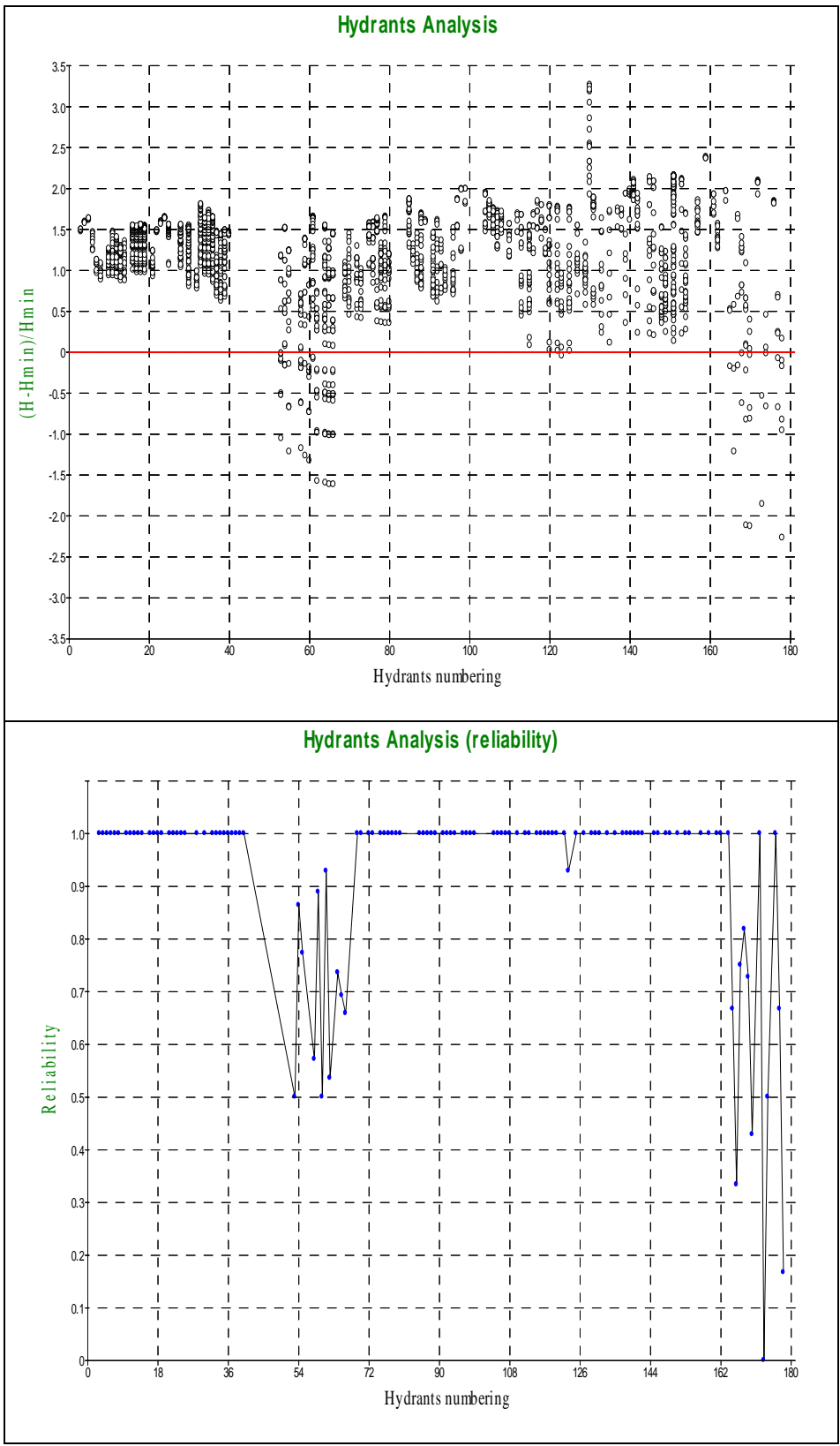

Fig. 22. Values of $R P D$ and $R$ obtained by simulating the restricted demand delivery scenario on the distribution network D8-S after implementing physical improvements. 


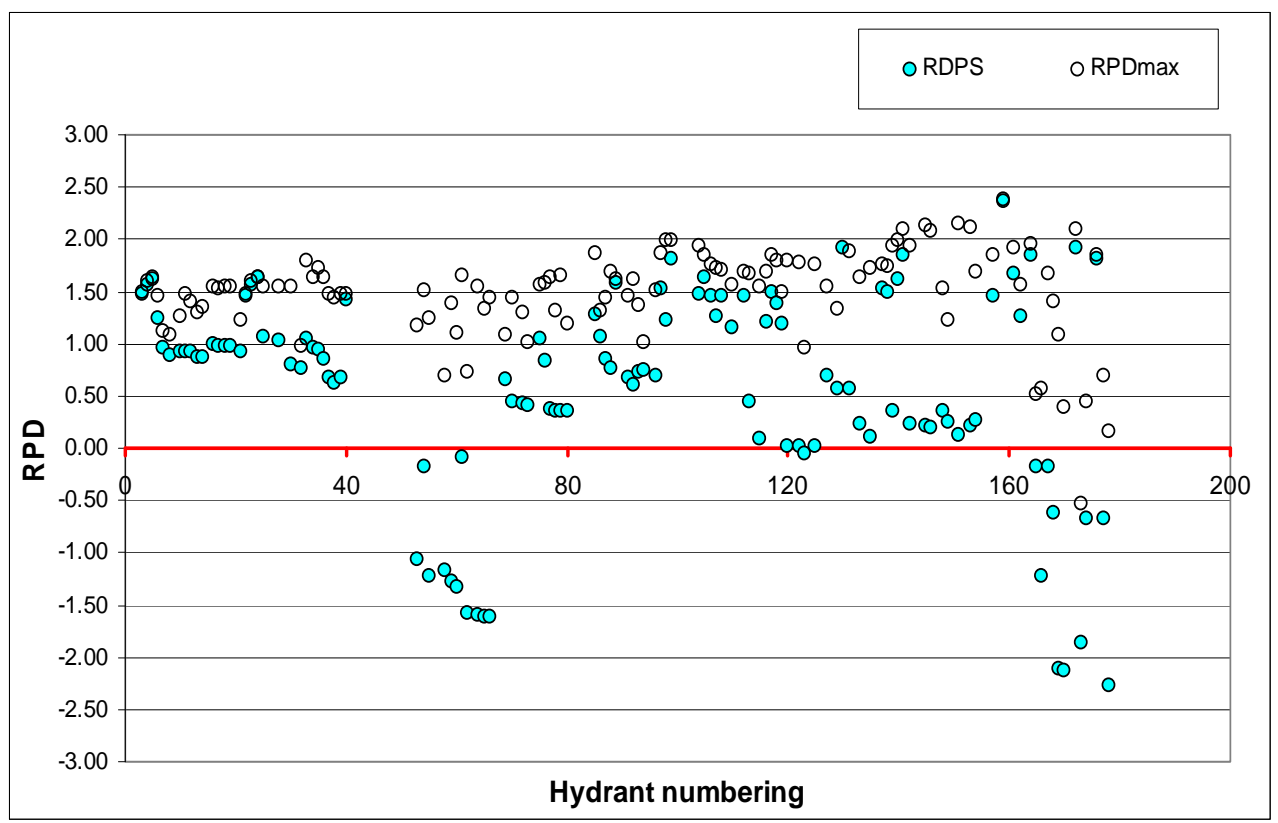

Fig. 23. RPDS values obtained simulating the restricted demand delivery scenario on the distribution network D8-S of District 10 after implementing the physical improvements.

\section{Summary and conclusions}

In this chapter, an innovative methodology aiming at diagnostic assessments of existing pressurized irrigation delivery networks is presented. The methodology entails the use of an agro-hydrological model for generating the demand flow hydrograph and the resulting flow configurations in the network, of a hydraulic simulation model to analyze its behavior under the simulated flow configurations, and of a set of performance indicators to evaluate the delivery achievements with respect to target or agreed-upon delivery objectives.

Both the agro-hydrological and hydraulic simulation models were tested and validated in previous research works and in different applications, proving their capability to forecast flow scenarios and the resulting hydraulic behaviors with adequate accuracy. The performance indicators were conceived and/or tailored for applications to pressurized networks and were tested for validation in previous research works conducted on a largescale system of southern Italy, on which water deliveries to farmers are recorded and stored at hydrant level for monitoring and water-billing purposes. 


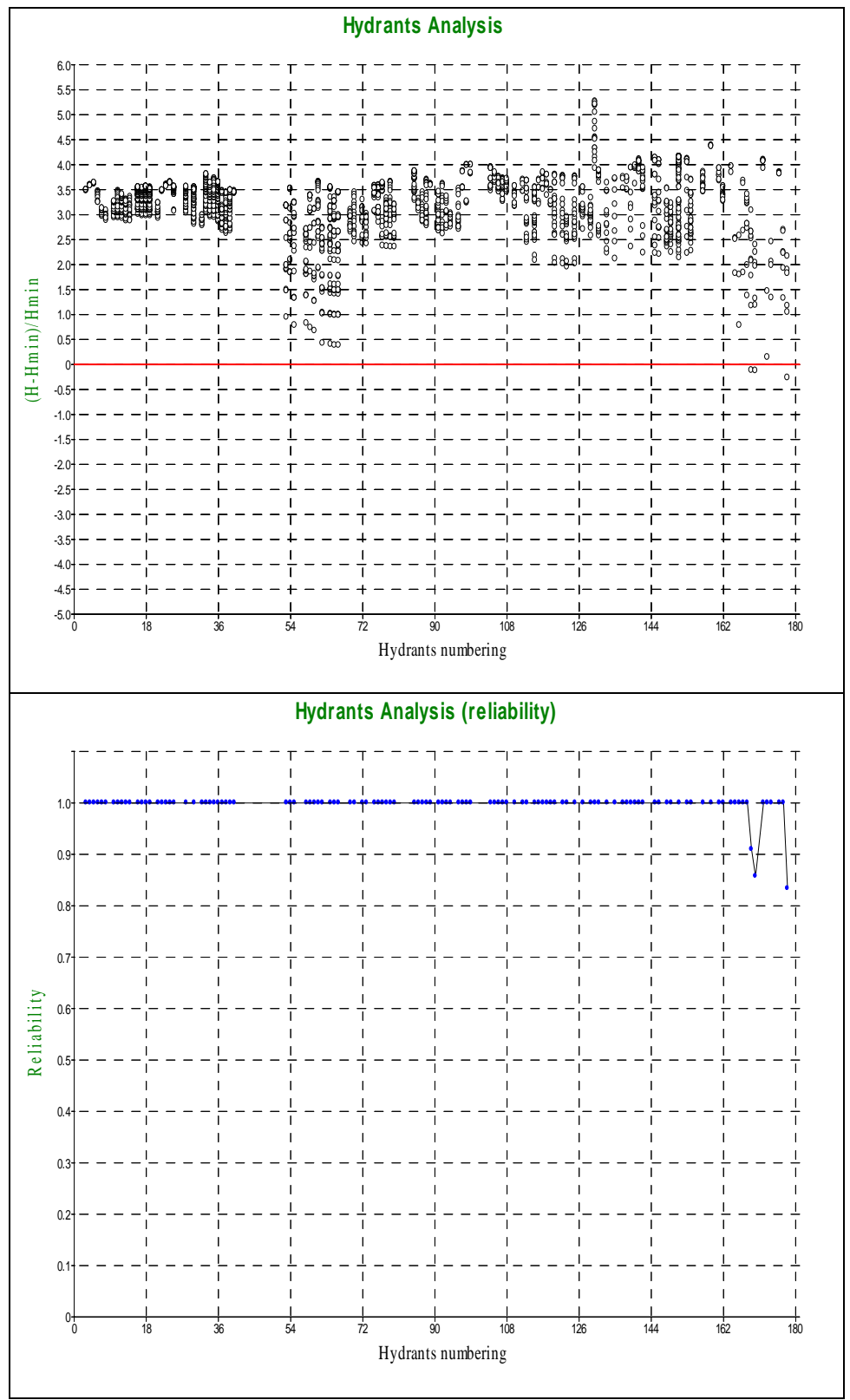

Fig. 24. $R P D$ and $R$ values obtained simulating the restricted demand delivery scenario on the distribution network D8-S after increasing the total piezometric heat to $126 \mathrm{~m}$ a.s.l. 


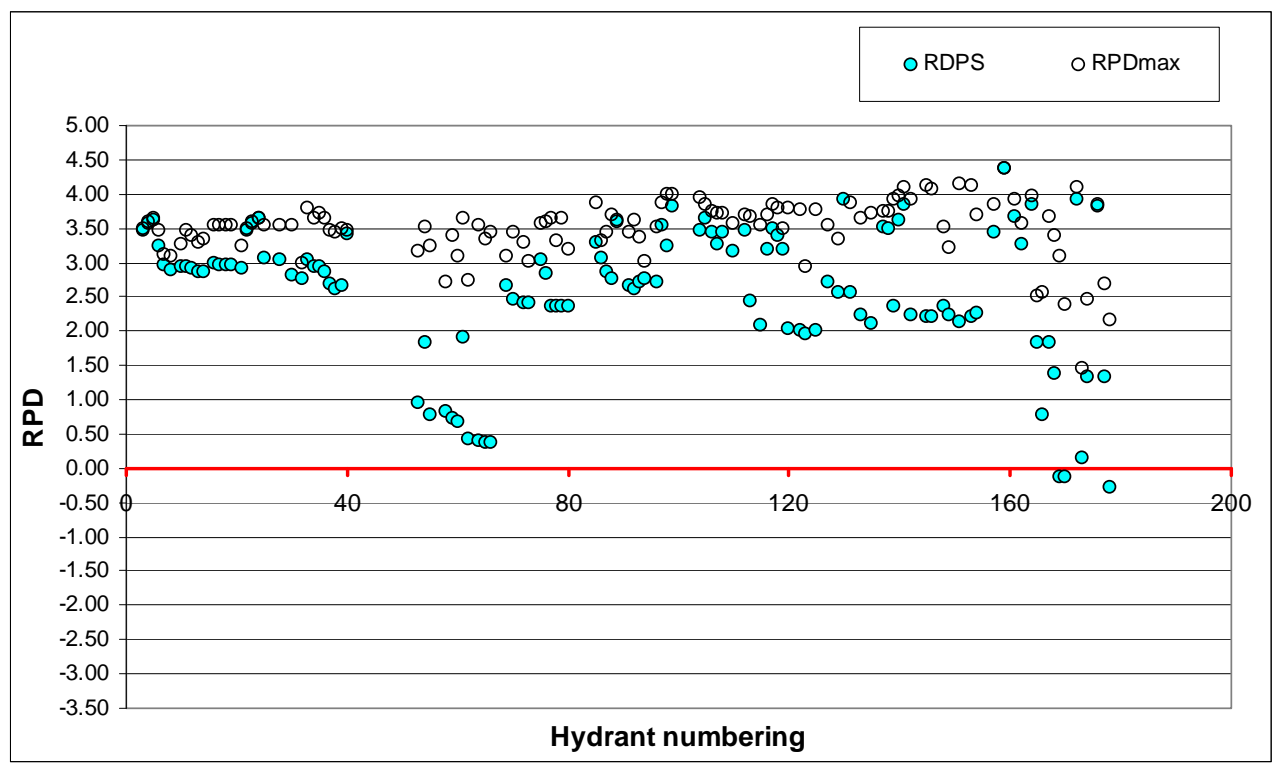

Fig. 25. RPDS values obtained simulating the restricted demand delivery scenario on the distribution network of D8-S after increasing the total piezometric head to $\mathrm{H}=126 \mathrm{~m}$ a.s.l.

Finally, the proposed methodology was applied to a large-scale irrigation system in need of modernization, and specifically to two tail-end irrigation districts, and enabled the analysis of networks performances under different flow configurations. This application showed the usefulness of the combined analysis and simulation tools for addressing physical and operational aspects of modernization in poor-performing delivery networks.

In this perspective, the proposed methodology can be utilized as an analytical framework for designing and sizing new irrigation delivery systems, as well as for modernizing and reengineering low performing systems, but also for assisting the management of irrigation schemes in developing operational plans and in avoiding situation of poor performance in water delivery to farmers.

\section{References}

Bethery J, Meunier M, Puech C (1981) Analyse des defaillances et etude de renforcement des reseaux d'irrigation par aspersion, Onzième Congrés de la CIID, question 36, pp. 297-324.

Bos MG, Burton MA, Molden DJ (2005) Irrigation and drainage performance assessment. Practical Guidelines. CABI Publishing, Cambridge, MA. ISBN 0851999670.

Burt CM, Styles SW (2004) Conceptualizing Irrigation Project Modernization Through Benchmarking and the Rapid Appraisal Process. In: "Irrigation and Drainage" (C)2004 of the International Commission on Irrigation and Drainage (ICID), John Wiley \& Sons, Inc. 
Clément R. (1966) Le calcul de débits dans le réseaux d'irrigation functionnant à la demand. La Houille Blanche 5: 553-575.

Clément R, Galand A (1979) Irrigation par aspersion et reseaux collectifs de distribution sous pression. Eyrolles Editeur, Paris.

CTGREF Division Irrigation (1974) Programme ICARE - Calcul des caracteristiques indicées. Note Technique 6.

Hashimoto T (1980) Robustness, Reliability, Resiliency and Vulnerability Criteria for planning water resource systems, Ph.D. Dissertation, Cornell University, USA.

Hashimoto T, Stedomger JR and Loucks DP (1982) Reliability, Resiliency and Vulnerability Criteria for water resources system performance evaluation. Water Resources Res 18(1): 14-20.

INEA (1999) Quadro di riferimento per lo studio è il monitoraggio dello stato dell' irrigazione in Puglia: Consorzio di Bonifica Stornara e Tara, Taranto.

Labye Y, Olson MA, Galand A, Tsiourtis N (1988) Design and Optimization of Irrigation Distribution Networks. Irrigation and Drainage Paper no. 44, FAO, Rome.

Lamaddalena N (1997) Integrated simulation modeling for design and performance analysis of on-demand pressurized irrigation systems, Ph.D Dissertation, Technical University of Lisbon, Portugal.

Lamaddalena N, Sagardoy JA (2000) Performance Analysis of on-demand pressurized irrigation systems. FAO Irrigation and Drainage Paper n. 59, Rome, pp 132.

Molden DJ, Gates TK (1990) Performance measures for evaluating irrigation water delivery systems. J Irrig Drain Eng, ASCE 116(6): 804-823

Murray-Rust DH, Snellen WB (1993) Irrigation system performance assessment and diagnosis (Joint publication of IIMI, ILRI and IHE). Colombo, Sri Lanka: International Irrigation Management Institute.

Plusquellec HL, Burt CM, Wolter HW (1994) Modern water control in irrigation. Concepts, issues, and applications. World Bank Technical Paper 246. Irrigation and Drainage series. World Bank.

Prajamwong S, Merkley GP, Allen RG (1997) Decision Support Model for Irrigation Water Management. J Irrig Drain Eng 123 (2), 106-113

Rao PS (1993) Review of selected literature on indicators of irrigation performance. Colombo, Sri Lanka: International Irrigation Management Institute.

Small LE, Svendsen M (1992) A framework for assessing irrigation performance. Working Papers on Irrigation Performance No. 1. Washinghton, D.C., International Food Policy Research Institute.

Zaccaria D, Oueslati I, Neale CMU, Lamaddalena N, Vurro M, Pereira LS (2010) Flexible Delivery Schedules to Improve Farm Irrigation and Reduce Pressure on Groundwater: a Case Study in Southern Italy. Irrig Sci 28:257-270, DOI 10.1007/s00271-009-0186-8.

Zaccaria D, Lamaddalena N, Neale CMU, Merkley G (2011a) Simulation of Peak-Demand Hydrographs in Pressurized Irrigation Delivery Systems Using A Stochastic Model. Part I: Model Development. Paper submitted to Irrigation Science on January 2011, manuscript ID IrrSci-2011-0010, currently under peer reviewing.

Zaccaria D., Lamaddalena N., Neale C.M.U., Merkley G. (2011b) Simulation of PeakDemand Hydrographs in Pressurized Irrigation Delivery Systems Using A 
Stochastic Model. Part II: Model Applications. Paper submitted to Irrigation Science on January 2011, manuscript ID IrrSci-2011-0011, currently under peer reviewing. 


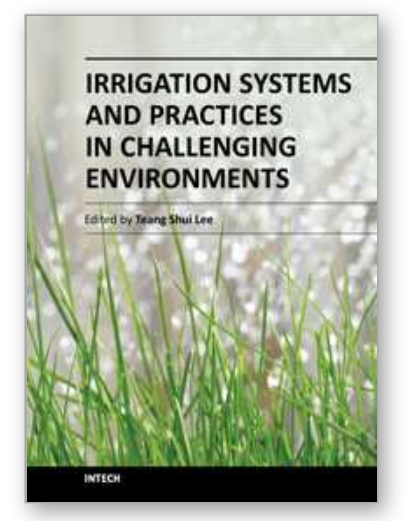

\author{
Irrigation Systems and Practices in Challenging Environments \\ Edited by Dr. Teang Shui Lee
}

ISBN 978-953-51-0420-9

Hard cover, 370 pages

Publisher InTech

Published online 28, March, 2012

Published in print edition March, 2012

The book Irrigation Systems and Practices in Challenging Environments is divided into two interesting sections, with the first section titled Agricultural Water Productivity in Stressed Environments, which consists of nine chapters technically crafted by experts in their own right in their fields of expertise. Topics range from effects of irrigation on the physiology of plants, deficit irrigation practices and the genetic manipulation, to creating drought tolerant variety and a host of interesting topics to cater for the those interested in the plant water soil atmosphere relationships and agronomic practices relevant in many challenging environments, more so with the onslaught of global warming, climate change and the accompanying agro-meteorological impacts. The second section, with eight chapters, deals with systems of irrigation practices around the world, covering different climate zones apart from showing casing practices for sustainable irrigation practices and more efficient ways of conveying irrigation waters - the life blood of agriculture, undoubtedly the most important sector in the world.

\title{
How to reference
}

In order to correctly reference this scholarly work, feel free to copy and paste the following:

Daniele Zaccaria (2012). Large-Scale Pressurized Irrigation Systems Diagnostic Performance Assessment and Operation Simulation, Irrigation Systems and Practices in Challenging Environments, Dr. Teang Shui Lee (Ed.), ISBN: 978-953-51-0420-9, InTech, Available from: http://www.intechopen.com/books/irrigation-systemsand-practices-in-challenging-environments/large-scale-pressurized-irrigation-systems-diagnostic-performanceassessment-and-operation-simulatio

\section{INTECH}

open science | open minds

\author{
InTech Europe \\ University Campus STeP Ri \\ Slavka Krautzeka 83/A \\ 51000 Rijeka, Croatia \\ Phone: +385 (51) 770447 \\ Fax: +385 (51) 686166 \\ www.intechopen.com
}

\author{
InTech China \\ Unit 405, Office Block, Hotel Equatorial Shanghai \\ No.65, Yan An Road (West), Shanghai, 200040, China \\ 中国上海市延安西路65号上海国际贵都大饭店办公楼405单元 \\ Phone: $+86-21-62489820$ \\ Fax: $+86-21-62489821$
}


(C) 2012 The Author(s). Licensee IntechOpen. This is an open access article distributed under the terms of the Creative Commons Attribution 3.0 License, which permits unrestricted use, distribution, and reproduction in any medium, provided the original work is properly cited. 